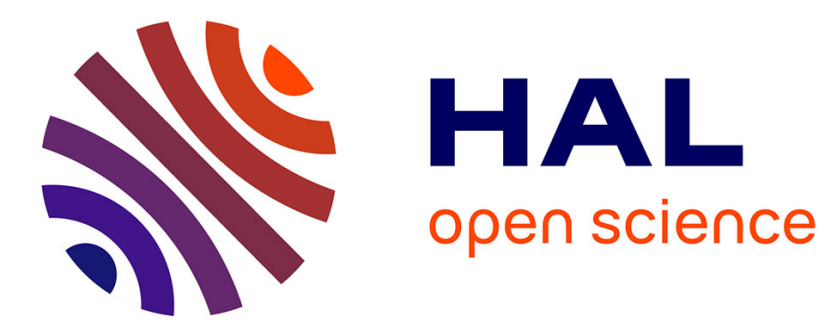

\title{
Molecularly imprinted polymers in miniaturized extraction and separation devices
}

Thomas Bouvarel, Nathalie Delaunay, Valérie Pichon

\section{To cite this version:}

Thomas Bouvarel, Nathalie Delaunay, Valérie Pichon. Molecularly imprinted polymers in miniaturized extraction and separation devices. Journal of Separation Science, 2021, 44 (8), pp.1727-1751. 10.1002/jssc.202001223 . hal-03283672

\section{HAL Id: hal-03283672 https://hal.sorbonne-universite.fr/hal-03283672}

Submitted on 12 Jul 2021

HAL is a multi-disciplinary open access archive for the deposit and dissemination of scientific research documents, whether they are published or not. The documents may come from teaching and research institutions in France or abroad, or from public or private research centers.
L'archive ouverte pluridisciplinaire HAL, est destinée au dépôt et à la diffusion de documents scientifiques de niveau recherche, publiés ou non, émanant des établissements d'enseignement et de recherche français ou étrangers, des laboratoires publics ou privés. 


\title{
Molecularly imprinted polymers in miniaturized extraction and separation devices
}

\author{
Thomas Bouvarel $^{1} \odot \quad \mid \quad$ Nathalie Delaunay ${ }^{1} \odot \quad \mid \quad$ Valérie Pichon $^{1,2} \odot$
}

${ }^{a}$ Laboratoire des Sciences Analytiques, Bioanalytiques et Miniaturisation - UMR Chimie Biologie Innovation 8231, ESPCI Paris, CNRS, PSL University, 75005 Paris, France bSorbonne Université, 75005 Paris, France

* Corresponding author: valerie.pichon@espci.fr (V. Pichon), Tel: +33 140794 772, Fax: +33 140794 776. LSABM, ESPCI Paris, 10 rue Vauquelin, 75005 Paris, France

Abbreviations: AA: acrylic acid; AIBN: azobisisobutyronitrile; $C L$ : cross-linker; $D C M$ : dichloromethane; EF: Enrichment factor; EGDMA: ethylene glycol dimethacrylate; HEMA: 2hydroxyethyl methacrylate; IA: itaconic acid; IF: imprinting factor; IS : immunosorbent; $M$ : monomer; MAA: methacrylic acid; MIP: molecularly imprinted polymer; N: efficiency; nanoLC: nano liquid chromatography; NIP: non-imprinted polymer; OS: oligosorbent; PDMS: poly(dimethylsiloxane); POSS: polyhedral oligomeric silsesquioxane; Rs: Resolution; T: Template; TRIM: trimethylolpropane trimethacrylate; VP: vinylpyridine; $\alpha$ : selectivity; $\gamma$ MAPS: 3-(trimethoxysilyl)propyl methacrylate.

Keywords: Miniaturization; Molecularly imprinted polymer; Monolith; Separation; Solidphase extraction.

\section{Abstract}

Molecularly imprinted polymers are highly selective and cost-effective materials, which have attracted significant interest in various areas such as sample pretreatment and chromatographic and electrophoretic separations. This review aims to present the state of the art concerning the miniaturization of these materials in order to meet the societal demand for reliable, fast, cheap, and solvent/sample saving analyses. The polymerization route specificities for the production of miniaturized molecularly imprinted polymers in capillaries or chip channels such as open tubular, packed particles, magnetic nanoparticles, and in situ imprinted monoliths are investigated. Their performances as selective supports in solid phase extraction and as stationary phases in electrochromatography and liquid chromatography, as well as their possible perspectives are discussed. 


\section{Introduction}

Molecularly imprinted polymers (MIPs) are synthetic materials possessing specific cavities with steric and functional complementarity towards a template molecule $(T)$ and involving a retention mechanism based on molecular recognition for analyte recognition or discrimination of chemical species of similar structure. MIPs can be considered as synthetic supports mimicking immunosorbents (ISs) or oligosorbents (OSs), to which they can be compared [1]. Indeed, they present a similar selectivity by the fact that these three supports generate a retention mechanism based on molecular recognition. While the development of ISs is expensive and require significant production times for antibodies, while a limited number of aptamer sequences are currently available for OS, MIPs offer many advantages including chemical and thermal stability but also easy, cheap, and rapid preparation for a wide variety of applications related to chemical and biological molecules. In return, the development of a selective MIP necessitates a careful and long optimization in order to be adapted to each type of sample and depends on the nature of the interactions developed and thus on the synthetic reagents used. They have been already successfully applied in several fields, such as drug delivery [2-4], sensors [5-8], or biomimetic catalyst in organic synthesis [9]. MIPs were also widely used as stationary phase in liquid chromatography (LC) [10-12] and capillary electrochromatography (CEC) [11-14] for separation of structural analogs and enantiomers $[15,16]$ or as sorbent for extraction, whether for the selective recognition of small molecules, such as drugs, pesticides, or other environmental pollutants [17-26], of proteins [27-29], or even of microorganisms [30].

In the extraction and separation fields, while early works used MIPs in the form of particles of more or less controlled sizes into disposable extraction cartridges or columns, depending on the application, many recent studies have shown that MIPs can be produced on a miniaturized scale as thin films or monoliths. Preparation of a miniaturized MIP allows the reduction of the required amount of template, which is often the most expensive reagent involved in the synthesis process [31]. More generally, the potential benefits of miniaturization are numerous, following the principle that small-scale processes consume less time, sample, and reagents and thus reduce the analysis costs, as well as the amount of waste [32]. In order to limit this reagent consumption and to tend towards well-defined small particle sizes, many groups have worked on the production of nanoparticles coated with a thin layer of MIP, mainly used for extraction in dispersive mode as recently reported [17], the purified extract being generally analyzed by conventional methods. However, in order to make the most of this miniaturization, all the different steps of the analytical procedure must be miniaturized and, if possible, integrated into a single device in order to move towards the concept of micro total analytical system ( $\mu$-TAS) introduced by Manz et al. [33] in the 90's and also called lab-on-chip. Among the miniaturized separation methods available, capillary electrophoresis (CE) and nano liquid chromatography (nanoLC) are predominantly employed. Therefore, for the integration of MIPs as stationary phases for separation or upstream as extraction sorbents, it is quite understandable that the preferred format for miniaturized MIPs has consisted in introducing them in a privileged way in fused-silica capillaries. They are multiple approaches for preparing a MIP in a capillary. The MIP can be available as particles of various sizes (down to nanoparticles and with possibly magnetic properties) held in the capillary. It is also possible to synthesize MIPs inside the capillary in the form of a thin porous film following an approach called open tubular or of a porous monolith filling the entire section of the capillary, which allows to overcome the constraints related to the use of particles (immobilization and 
homogeneous packing) or thin films (low amount of phase), while providing a high specific surface area and a high permeability [34]. Finally, in order to go further in the miniaturization and integration of MIPs into the overall analysis procedure and thus respond to the $\mu$-TAS concept previously mentioned, many groups have integrated MIPs in a chip using approaches similar to those used with capillaries.

Based on the published works, this paper aims first to present and discuss the different ways in which miniaturized MIPs can be prepared for use as extraction or separation media in capillary or on-chip format. Their potential as a stationary phase for separation in CEC and nanoLC and, in a second step, as a sorbent for selective solid phase extraction (SPE) are discussed. However, since this review focuses exclusively on exhaustive extraction, applications such as solid phase microextraction and dispersive solid phase extraction will not be covered.

\section{Generalities on molecularly imprinted polymer synthesis}

MIP synthesis generally consists first of a complexation in solution of a template molecule with functional monomers $(\mathrm{M})$ via non-covalent bonds. A cross-linker $(\mathrm{CL})$ and an initiator are then introduced to generate polymerization of the monomers around the template, either by thermal or photochemical initiation. After polymerization, the template molecules are removed by extensive washing steps, resulting in available cavities complementary to the template in terms of shape, size, and position of functional groups.

In most cases, the targeted analyte is very often used as template. Its structure and functionalities define the properties of the synthesized binding sites, ensuring optimal recognition during the extraction or separation process. However, the complete removal of the template molecules from the MIP can be incomplete or difficult to achieve despite extensive washing steps with large volumes. The residual template leakage from the MIP can lead to erroneous quantification, especially when applied in trace analysis. In this case, the use of a structural analog as template for the MIP synthesis that can be distinguished from the target analyte during its determination, especially by chromatographic methods, constitutes an easy way to limit the risk and is called dummy approach [35-40].

Despite the wide variety of targets and templates employed, reagents used for the polymerization are recurrent. Among them, the functional monomers generally chosen are methacrylic acid (MAA), acrylic acid (AA), itaconic acid (IA), 2-hydroxyethyl methacrylate (HEMA), or vinylpyridine (VP) [17]. The most commonly used cross-linkers are bifunctional ethylene glycol dimethacrylate (EGDMA) and divinylbenzene or trifunctional trimethylolpropane trimethacrylate (TRIM). In order to promote formation of the templatemonomer complex, the polymerization solvent is selected to favor the desired interactions, for example hydrogen bonds and electrostatic interactions. Therefore, it is better in this case to employ, whenever possible, a weakly polar and aprotic solvent such as toluene, dichloromethane (DCM), chloroform, and acetonitrile (ACN) or a mixture of them.

The performance of a MIP is related to the occurrence of cavities that promote highly selective interactions between the polymer and target compounds. In most of the works, a nonimprinted polymer (NIP) is synthesized with exactly the same conditions as MIP except that the template is omitted. This control polymer, that does not possess any specific cavities, is studied in parallel during the MIP characterization. Because of the use of the same reagents, this non-imprinted support allows the evaluation of the contribution of the non-specific 
interactions occurring between a given compound and the NIP surface that exist also at the MIP surface.

\section{Open-tubular molecularly imprinted polymers}

\subsection{Preparation of open tubular molecularly imprinted polymers}

The first miniaturized MIPs were synthesized as a porous thin film on the inner surface of a capillary [41,42]. Until today, numerous MIPs prepared following such an open tubular approach in capillaries have been reported as shown in Table 1. Before starting the synthesis, most of these studies reported the use of 3-(trimethoxysilyl)propyl methacrylate ( $\nu$-MAPS) in a first step to ensure the future anchoring of the film to the inner wall of the capillary [42-54]. This reagent has a trifunctional silane group that can bind the capillary silica wall as well as a function that will participate to the polymerization of the MIP.

The reagents predominantly used are MAA coupled with the cross-linker EGDMA and a thermal [42-47,49-52] or photochemical [48,53-55] initiation with azobisisobutyronitrile (AIBN). The most commonly employed porogens are ACN [42-47,49,53-55] and toluene $[42,48,50,52,55]$ with the addition of small amount of isooctane $[43,45,50,52]$ or decanol $[48]$ to increase the specific surface area, or even 2-propanol $[44,46,47]$ to ensure the complete dissolution of each reagent. Wu et al. employed a special ternary porogen system (toluene, isooctane, and DMSO) to solve the solubility problem encountered using D-zopiclone, a very polar compound, as template [52]. However, as DMSO strongly affects the morphology and separation performance of MIP, its content must be carefully optimized. In order to control the film thickness, a thermal initiation (from 50 to $75^{\circ} \mathrm{C}$ ) and a short polymerization time (from $10 \mathrm{~min}$ to $4 \mathrm{~h}$ ) are adopted [42-46,48-52]. In some publications a pressure is applied after the polymerization to shrink the polymer into a thin film against the capillary wall $[42,48,49]$.

The first evaluation of a MIP thin film consists generally in observing the inner section of the capillary by scanning electron microscopy (SEM) to check the good anchorage of the MIP layer. This also makes possible to determine the approximate thickness of the film, which ranges from 0.1 to a few micrometers with a single study up to $10 \mu \mathrm{m}$ [52].

The dimensions of the devices fluctuate significantly, but it is possible to observe some trends depending on the chosen application. The open tubular MIPs for CEC or nanoLC applications are mainly produced in capillaries of $25 \mu \mathrm{m}[42-45]$ and $50 \mu \mathrm{m}[46-48,55]$ of internal diameter (i.d.), although larger diameters of 75 [49] and $100 \mu \mathrm{m}$ [50-52] can be found. For extraction applications, i.d. of the capillaries are $100 \mu \mathrm{m}[53,54]$. Concerning the MIP lengths, they are heterogeneous with most often 5 to $50 \mathrm{~cm}$ of MIP layer length for separation purposes, and from few millimeters to several centimeters for extraction purposes.

\subsection{Applications of open tubular molecularly imprinted polymers}

As illustrated by works listed in Table 1, MIPs obtained by open tubular approach were used mainly as stationary phases in CEC $[42-47,49-52,55]$ and to a lesser extent in nanoLC $[42,48]$ and as SPE sorbent $[53,54]$. Indeed, this approach offers several advantages for separation since it generates low back pressure and fast mass transfer. In order to evaluate the MIP performances, different parameters can be measured such as selectivity $(\alpha)$, resolution $\left(R_{S}\right)$ or efficiency $(N)$ and are reported in Table 1. A large majority of publications dealing with open tubular MIPs for CEC $[42-46,50-52,55]$ or LC $[42,48]$ have been dedicated to the separation 
of enantiomers. In this case, high resolution or selectivity values resulting from a stronger retention of the enantiomer used as template clearly indicate the contribution of the specific cavities in the retention mechanism.

Tan et al. were the first to use an open tubular MIP for the baseline enantioseparation of dansyl-D,L-phenylalanine in both CEC and nanoLC modes [42]. Recently, Zhao et al. [50] exploited the advantages of the addition of a polyhedral oligomeric silsesquioxane (POSS) as monomer to improve the MIP performances by taking advantage of rigidity reinforcement at the molecular level. This hybrid organic-inorganic MIP was applied to the CEC enantioseparation of amlodipine and an average efficiency $\mathrm{N}$ of $3.35 \times 10^{4}$ plates $\mathrm{m}^{-1}$ together with a $R_{s}$ of 14.84 were obtained, much more lower performances being obtained with a POSSfree MIP $\left(N=11,300\right.$ plates $\left.\mathrm{m}^{-1} ; \mathrm{R}_{\mathrm{s}}=7.63\right)$.

MIPs were also used in open tubular CEC for non-chiral separation of structural analogs such as nucleotide bases [49] or profen drugs [44]. However, this type of application requires the use of a NIP. Indeed, while in chiral separation a high resolution reveals the presence of cavities, for the separation of analogs of different polarities, the presence of cavities can only be proven by the measurement of a different retention strength/order on NIP.

Zaidi et al. performed both chiral separation of ketoprofen and non-chiral separations of naproxen, ibuprofen, and fenoprofen in long capillaries of different lengths $(1,2$, or $3 \mathrm{~m} x$ $50 \mu \mathrm{m}$ i.d.) with a MIP approximately 1-4 $\mu \mathrm{m}$ thick [44]. The synthesis conditions incorporated 4-styrenesulfonic acid in the imprinted poly(MAA-co-EGDMA) to enable a strong and stable electroosmotic flow (EOF) at the optimized pH [46]. The enantioseparation as well as nonchiral separation of profen drugs were successfully accomplished on each column, as shown in Figure 1, with a resolution of 4.0 for the ketoprofen racemic with the capillary of $1 \mathrm{~m}$ long and an impressive average efficiency of $1,000,000$ plates $\mathrm{m}^{-1}$. A batch-to-batch $\operatorname{RSD}\left(\mathrm{n}_{\mathrm{B} / \mathrm{B}}=3\right)$ lower than $2.3 \%$ for the efficiency was observed, indicating a very good synthesis repeatability despite the long length of the capillaries [44].

An atypical device was proposed by Jang et al. by interfacing a S-ketoprofen imprinted poly(MAA-co-4-styrenesulfonic acid-co-EGDMA) open-tubular capillary with a nanospray interface utilizing a sheath flow for electrospray ionization and tandem mass spectrometry, in order to simultaneously separate and characterize phospholipids in human urinary lipid extracts [47]. The phospholipids were separated by their acyl chain length and polar head groups, allowing the identification of 18 of them. However, the selectivity remains to be demonstrated since no NIP was synthesized.

$\mathrm{Qu}$ et al. developed a dual-template L-tyrosine and L-tryptophan imprinted poly(AA-coEGDMA) for CEC multiple enantioseparation [45]. However, the authors decided to go further by integrating the fused-silica capillary containing the open tubular MIP phase $(6 \mathrm{~cm}$ length, $25 \mu \mathrm{m}$ i.d., and MIP layer about $2 \mu \mathrm{m}$ thick) inside a poly(dimethylsiloxane) (PDMS) chip with a carbon fiber microdisk electrode for detection. The separation of both racemic tyrosine and tryptophan was performed within $120 \mathrm{~s}$ with $\mathrm{R}_{\mathrm{s}}$ values of 1.02 and 1.00 , respectively. It is also important to highlight the effort that was made in determining RSDs $(n=6)$ of retention time and peak area for run-to-run (1.2-1.8\% and 2.6-3.9\%, respectively), day-to-day (2.4-2.7\% and 4.3-7.1\%, respectively), and chip-to-chip (3.8-5.2\% and 5.9-8.8\%, respectively), suggesting that the method had good stability and repeatability but also that the imprinted chips had good manufacturing reproducibility. The same team produced also a hybrid microchip with a capillary ( $8 \mathrm{~cm}$ length, $25 \mu \mathrm{m}$ i.d., and MIP layer about $2.5 \mu \mathrm{m}$ thick) containing a N-(tertButoxycarbonyl)-L-tryptophan imprinted poly(AA-co-EGDMA) film [43]. A resolution of 1.27 was achieved in $75 \mathrm{~s}$ with similar performances in terms of reproducibility and stability. 
For its use in extraction, the open tubular approach suffers from a low surface-to-volume ratio as the amount of MIP represents only a small part of the volume of the capillary. Therefore, the resulting limited capacities seem particularly problematic for such an application. A MIP film was used as SPE sorbent by constituting an in-line concentrator $(5 \mathrm{~cm} \times 100 \mu \mathrm{m}$ i.d. with an unknown film thickness) directly inside the capillary of a CE-UV system for the determination of bisphenol A [54]. Recovery of 86.7-108.6\% were obtained for tap water, river water, beverage, and urine with RSD values of $2.0-5.6 \%$ for bisphenol A. The LOD was evaluated in pure medium at $0.8 \mathrm{ng} \mathrm{mL}^{-1}$ which is over 100 -fold better than that of direct CE determination. A similar in-line coupling of a MIP $(3 \mathrm{~mm} \times 100 \mu \mathrm{m}$ i.d., unknown film thickness) with CE-UV was reported [53]. Enrichment factor (EF) of about 200 was calculated for the extraction of epitestosterone, methyltestosterone, and testosterone from pure medium and the authors also indicated that the coated MIP layer maintained good operational performance after more than 100 cycles. Nevertheless, if the enrichment was proven in both studies, the evaluation of non-selective interactions was not fully considered because the synthesis of a NIP was not reported.

\section{Molecularly imprinted polymer particles packed in capillary or chip channel}

\subsection{Packing of particles}

Miniaturized MIP devices can also be prepared by packing MIP particles in capillaries or in microchannels of chips. By filling the entire section of the capillary or channel, it allows the overcoming of the lack of capacity of the open tubular format. However, frits or restrictions are required to maintain particles. Frits are tricky to obtain as they should withstand high pressures, be porous enough, and should not be too long or interact with the analytes [13]. In addition, the presence of frits is propitious to the generation of air bubbles. Numerous other methods were adopted to immobilize particles such as the use of acrylamide gel inside capillary [56] or using particles with diameters of 55-57 $\mu \mathrm{m}$ similar to the i.d. of the separation capillary (50 or $75 \mu \mathrm{m}$ i.d.) in order to generate an agglomerate just before the separation capillary without frits $[57,58]$. Concerning chip device, the particles can be immobilized by designing a micro-cell containing the particles of larger dimensions than the other channels of the chip and thus generating a restriction $[59,60]$.

MIP particles can be obtained by synthesizing the imprinted polymer by bulk polymerization and the resulting MIP, obtained as a monolith is next crushed and sieved during several cycles, giving rise of MIP particles with diameters between 50 and $110 \mu \mathrm{m}$. This heterogeneity in the resulting particle size may represent a first drawback since it may be damaging for separation purposes thus explaining their used as extraction device as illustrated by works reported in Table 2 [57-60].

More homogeneous MIP particles can be obtained by imprinting the surface of core particles. This approach has contributed to the strong expansion of the use of MIP particles in dispersive solid phase extraction as recently reviewed $[17,61,62]$. In most cases, the core sorbents are particles with magnetic properties to facilitate the extraction workflow by replacing the long and tedious centrifugation step by the application of magnetic field to recover the particles. These properties were also exploited to immobilize MIP particles into miniaturized separation or extraction devices by applying an external magnetic field, thus eliminating the necessity of frits. For this purpose, particles of different natures, mainly $\mathrm{Fe}_{3} \mathrm{O}_{4}$ particles [63-65] as shown in Table 3 with diameters between 25 and $385 \mathrm{~nm}$ were selected. After activating the surface 


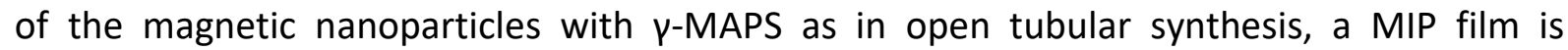
synthesized either using conventional reagents such as MAA and EGDMA [66] or by exploiting the self-polymerization of dopamine and norepinephrine [63-65] giving rise to film thicknesses of 87-88 $\mathrm{nm}$ and 6-8 $\mathrm{nm}$, respectively. To be used, the MIP magnetic nanoparticles were directly filled in chip channels [63-65] or introduced into a capillary which was then integrated into a chip [66], the part occupied by the particles (ranging from $5 \mathrm{~mm}$ to $2 \mathrm{~cm}$ ) being tuned according to the magnet positioning.

Considering the difficulties to maintain particles in capillaries or channels by the previously described methods, it could have been interesting to have information related to the filling repeatability and its impact on MIP performances. This has only been discussed once [58] by Moreno-González et al. who studied the repeatability after constructing three MIP concentrators by inserting the capillary containing the MIP particles ( $2 \mathrm{~mm} \times 150 \mu \mathrm{m}$ i.d.) and the one dedicated to the CE separation $(130 \mathrm{~cm} \times 50 \mu \mathrm{m}$ i.d.) into a Teflon tube. The RSD $(n=10)$ values of peak areas of ten consecutive injections ranged from 3.4 to $9.8 \%$ and for the three different concentrators ranged from 5.1 to $10.4 \%$.

\subsection{Applications of packed molecularly imprinted polymer particles-based devices}

Only one separation device was based on the filling on $3 \mathrm{~mm}$ length of a $20 \mathrm{~cm} \times 75 \mu \mathrm{m}$ i.d. capillary by 2-10 $\mu \mathrm{m}$ particles obtained by grinding and immobilized with frits made of an acrylamide gel [56]. It was applied to the enantioseparation of phenylalanine and a resolution of 1.43 between both enantiomers was obtained, no information on the efficiency, repeatability, and lifetime of the system being available. However, the heterogeneity of MIP particles prepared by bulk process are known to exhibit low separation performance in terms of efficiency thus explaining why more homogeneous MIP particles obtained by surface imprinting were mainly used for separation in CEC [63-66]. High efficiency of such separation device is also favored by the fact that the MIP layer represents only a small part at the surface of the core magnetic particle. This allows the limitation of the diffusion of the compounds within the particles. Among the works based on surface imprinting, Qu et al. [66] designed a microfluidic device for rapid CEC enantioseparation of ofloxacin. As shown in Figure 2, MIP particles were introduced in a fused-silica capillary of $25 \mu \mathrm{m}$ i.d. integrated in a PDMS chip and maintained in the capillary to a defined place by applying an external magnetic field. It was found that the tunable length was optimal for $5 \mathrm{~mm}$ and led to a resolution of 1.46 with an analysis time of $195 \mathrm{~s}$. No enantioseparation was achieved with the NIP particles thus demonstrating the selectivity of the MIP. RSD values of retention time and peak area $(n=3)$ between 1.1 and $8.3 \%$ for run-to-run, day-to-day, and chip-to-chip suggest a good stability and fabrication reproducibility.

Separation efficiencies of $7.85 \times 10^{4}$ and $1.75 \times 10^{5}$ plates $\mathrm{m}^{-1}$ for $\mathrm{D}$ and L-tryptophan respectively were also obtained with particles coated with L-tryptophan imprinted poly(dopamine) film [63]. The resolution was about 1.65 and the analysis time was inferior to $1 \mathrm{~min}$. The RSD values of the retention times for run-to-run, day-to-day, and chip-to-chip were less than $5 \%$. Furthermore, the stability of MIP particles was demonstrated by storing them at $4^{\circ} \mathrm{C}$ for at least two weeks with no obvious effect on the analysis performance. However, after one month of storage the resolution was lowered to $91 \%$ of the initial value. The analytical performances were further improved by replacing the poly(dopamine) coating by a poly(norepinephrine) one and a resolution of 1.84 was obtained with efficiencies estimated to be about $1.28 \times 10^{5}$ and $1.83 \times 10^{5}$ plates $\mathrm{m}^{-1}$ for $\mathrm{D}$ - and L-tryptophan, respectively, for a 
packing length of $1 \mathrm{~cm}$ [64]. RSD values were similar to the ones of the previous study. The use of a mixture of nanoparticles resulting from the same synthesis route with three different templates (S-ofloxacin, L-tryptophan, and S-binaphtol) was also reported to carry out the simultaneous separation of different chiral analytes within $120 \mathrm{~s}$ in a single run [64].

A similar chip was constructed with a R-mandelic acid imprinted poly(norepinephrine) film [65]. A resolution of 1.82 was obtained and the separation efficiencies were calculated to be $3.2 \times 10^{3}$ and $5.4 \times 10^{3}$ plates $\mathrm{m}^{-1}$ for S- and R-mandelic acid, respectively. The run-to-run repeatability was evaluated with RSD $(n=6)$ of $2.3-2.5 \%$ and $3.1-3.6 \%$ on retention times and peak areas, respectively. The good reproducibility of the manufacturing process was also checked with RSD ( $n=3$ ) of 3.3-4.6\% on retention times. Finally, the authors proposed a knowhow transfer, using L-histidine as template molecule, allowing to perform the enantiomer separation with a resolution of 1.63 [65].

For SPE applications, retention capacity is more important than efficiency and this is why the use of MIP film obtained by surface imprinting is marginal as this approach can lead to limited capacity, as mentioned above for the open tubular format. As particles obtained by bulk synthesis are integrally made of MIP, the capacity provided by these particles is of obvious interest for this type of applications.

Among the few reported works, Z-L-phenylalanine-nitrobenzoxadiazole MIP particles $(<110 \mu \mathrm{m})$ were packed in a channel having an i.d. of $220 \mu \mathrm{m}$ in a poly(methylvinylsiloxane) chip and immobilized via a restriction channel (105 $\mu \mathrm{m}$ i.d.) [60]. The imprinted effects were evaluated by loading $20 \mu \mathrm{L}$ of a $1.10^{-6} \mathrm{~mol} \mathrm{~L}^{-1}$ of Z-L-phenylalanine-nitrobenzoxadiazole in acetonitrile (porogen of the synthesis) and on-line detected by laser induced fluorescence (LIF). The extraction recoveries were $61 \%$ for MIP and $18 \%$ for NIP, suggesting that a selective retention was obtained on MIP for pure media.

Commercial MIP particles were also used as extraction sorbent to carry out SPE coupled inline with CE separation $[57,58]$. The concentrators were constructed in a first capillary $(2 \mathrm{~mm}$ $x 150 \mu \mathrm{m}$ i.d. $x 360 \mu \mathrm{m}$ outer diameter (o.d.)) that was then coupled via a Teflon tube ( $300 \mu \mathrm{m}$ i.d.) to a second capillary (50-75 $\mu \mathrm{m}$ i.d. $\times 360 \mu \mathrm{m}$ o.d.) dedicated to the CE separation. These devices were applied to the analysis of triazines in spiked urine [57] and of eight regulated veterinary quinolones in bovine milk samples [58].

\section{Monolithic molecularly imprinted polymers}

Monolithic MIPs are prepared using organic or hybrid organic-inorganic monomers but also by surface imprinting on a core monolith. They were first prepared at conventional format in in the whole section of $4.6 \mathrm{~mm}$ i.d. stainless-steel columns as reported by Ou et al. $[67,68]$ and more recently by other groups [69-72]. However, their synthesis in capillaries or channels represents today most of the developments. Since this review aims to list miniaturized monolithic MIPs, a maximum i.d. value of $530 \mu \mathrm{m}$ has been defined.

\subsection{In situ synthesis of monolithic molecularly imprinted polymers}

\subsubsection{Organic monolithic molecularly imprinted polymers}

As for the largest scale, miniaturized monolithic MIPs were mainly synthesized using organic monomers ( $80 \%$ of the studies reported in Table 4 ) because numerous types of monomers are available and the polymerization procedure is simple [10]. Organic polymers benefit also 
from an excellent stability at different $\mathrm{pH}$ and their surface chemistry and porosity can be tuned [34] that is favorable for their in situ synthesis in capillaries or channels.

As illustrated by Table 4, most of miniaturized monolithic MIP syntheses were carried out in fused-silica capillaries that must be first activated to ensure the anchorage of the monolith at their inner surface. As for open tubular, $\mathrm{y}$-MAPS is the favored compound although other reagents such as 3-(triethoxysilyl)propyl methacrylate [35-37,73] or vinyltrimethoxysilane [74] were also sometimes used. SEM observations can be used to verify the correct anchorage of the imprinted monolith after its in situ polymerization and also to observe the influence of some parameters such as solvents [75-77] or monomers [38,78] on the morphology of the monolith, i.e. the presence of macropores that ensure its permeability which is an important parameter to consider.

As for MIP synthesis in bulk, MAA is the most commonly used functional monomer usually copolymerized with EGDMA as cross-linker, but AA [35-37,77] and VP [35-37,75,79] were sometimes preferred. The $\mathrm{T} / \mathrm{M} / \mathrm{CL}$ ratio is highly variable but a preponderance of publications used a molar ratio of $1 / 4 / 20$ [80-86]. Finally, miniaturized organic monolithic MIPs were mainly prepared by free radical polymerization with AIBN by either a photochemical or thermal initiation.

The choice of the polymerization solvent is one of the key factors and is the biggest change from classical bulk synthesis. Indeed, in addition to solubilize the reagents and promote interactions between the template and the functional monomers, it must led to large pores to obtain good flow-through property, i.e. a high permeability [87]. Therefore, a solvent is selected, such as predominantly ACN or toluene, to solubilize the reagents and promote the expected interactions and another solvent is added, such as dodecanol [35-37,75,79$82,85,88,89]$ or isooctane $[77,84,86,90-93]$, for its ability to produce large pores due to earlier onset phase separation. Appropriate ratios of each solvent are then adjusted to set the solubility, polarity, and ability to generate pores to a satisfactory degree.

The permeability of a monolithic MIP can be easily measured and calculated by the Darcy's law $[40,86,94-98]$ formulated with the following equation:

$$
\mathrm{K}=\frac{4 \eta \mathrm{LF}}{\pi \mathrm{d}_{\mathrm{i}}^{2} \Delta \mathrm{P}} \quad \text { (Equation 1) }
$$

$\mathrm{K}$ is the permeability $\left(\mathrm{m}^{2}\right), \mathrm{F}$ is the mobile phase flow rate $\left(\mathrm{m}^{3} \mathrm{~s}^{-1}\right), \eta$ is the mobile phase viscosity (Pa s), $L$ is the capillary length $(\mathrm{m}), \mathrm{S}$ is the section $\left(\mathrm{m}^{2}\right)$, and $\Delta P$ is the back pressure (Pa) generated by the monolithic MIP in the capillary or channel. The measured permeabilities reported in literature cover a wide range from $3.3 \times 10^{-15}$ [86], $1.5 \times 10^{-14}$ [94], to 1.5-7.2 $\times 10^{-}$ ${ }^{11} \mathrm{~m}^{2}$ [95-98]. Some of these publications have shown the influence of the solvent ratio on permeability $[86,94]$, while others have shown the influence of the synthesis temperature [40].

Since the potential of a MIP is related to cavities promoting highly selective interactions that should be absent in its NIP, other physical characterizations can be done. Nitrogen adsorption porosimetry was used to measure the surface area $[73,94,96-101]$ or pore volume $[73,94,102]$ of MIPs/NIPs. Fourier transform infrared [38,39,74,76,77,93-95,97,98,100-107] or solid-state UV-vis $[38,77,100,102,105]$ was also used to determine the characteristic chemical functions that make up the MIPs and NIPs. By comparing the spectra before and after the template removal, it is possible to confirm that this step was successfully completed. However, all these measurements can only be done with monoliths synthesized in larger dimensions and are 
therefore not fully representative of the miniaturized monoliths really synthesized in a capillary or channel.

\subsubsection{Hybrid organic-inorganic monolithic molecularly imprinted polymers}

Although predominantly reported, organic monoliths exposed to different solvents may shrink or swell [34]. These perturbations may alter the morphology and structure of the polymer network, thus affecting its performances. Hybrid monolithic MIPs benefit from the advantageous features of both the organic (simple polymerization procedures but also tunable porosity and surface chemistry) and inorganic (excellent mechanical strength and good solvent resistance) materials [34].

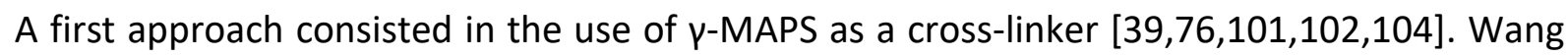
et al. even combined this reagent with a ternary porogen made of an ionic liquid, acetonitrile, and chloroform [102]. Thus, a poly(MAA- $\nu$-MAPS) imprinted with S-naproxen was synthesized under a non-hydrolytic sol-gel process, that does not require aging and drying steps at high temperatures but also avoids the cracking and shrinking phenomena. The ionic liquid has properties including a high ionic strength that increase the rate of aggregation. Lin et al. also succeeded in synthesizing an hybrid monolithic MIP, where polycondensation and polymerization were subsequently carried out in a $25 \mathrm{~cm} \times 75 \mu \mathrm{m}$ capillary, with lysozyme protein as template [94]. The poly(MAA-MBAA-TMOS)-based MIP allowed the combination of the rigidity from silica matrix and the flexibility from organic hydrogel.

\subsection{Synthesis of a molecularly imprinted polymer at the surface of a monolithic core}

Instead filling the whole section of a capillary or a channel, MIP can be prepared as a layer at the surface of an organic or inorganic core monolith, as described in Table 5. This approach takes advantage of the permeability and large specific surface area of the core monolith and of a reduced amount of template to synthesize a MIP in closer conditions of bulk synthesis. This explains the absence of dodecanol and isooctane in the porogen composition for most of the reported works $[40,100,108,109]$. However, the resulting volume of MIP phase is intermediate between that obtained by open tubular approach and by filling the entire section of the capillary by a monolithic MIP.

Organic core monolith based on poly(TRIM) [40,109-111] or inorganic poly(TMOS) monolith formed by sol-gel process $[100,108]$ were reported. In a second step, template, monomer, cross-linker and solvents, the same as in conventional MIP synthesis, are introduced to produce the thin film of MIP on the core monolith. In the reported works, the polymerization was initiated with AIBN either thermally $[40,100,108,111]$ or photochemically $[40,109,110]$. To develop a MIP for a glycoprotein, Lin et al. [99] reported the synthesis on a core monolith based on 4-vinylphenylboronic acid as monomer. The polymerization of the MIP layer using dopamine was induced after the complexation of horseradish peroxidase by its glycans (by their diol moieties) with the boronate functionalities of the core monolith allowing the orientation of the protein.

In the particular case of MIPs synthesized on a monolithic core, the permeability measurement was reported only once, being equal to $0.3-1.8 \times 10^{-14} \mathrm{~m}^{2}$, also showing the influence of the synthesis temperature on this parameter [40]. Further information can be obtained from other characterization techniques (porosity or specific surface) even if they were always performed with a larger material. Moreover, SEM can give an estimated thickness of the 
monolithic MIP coating as reported in a single study at a value of about $0.2 \mu \mathrm{m}$ [111]. The thickness of this film represents a clear advantage for the separation but the low quantity of MIP makes these materials relatively unsuitable for extraction, which explains why most of the materials obtained via this synthesis pathway were dedicated to separation, whether in CEC $[100,108,111]$ or nanoLC $[99,108-110]$.

\subsection{Monolithic molecularly imprinted polymers for separations in CEC and nanoLC}

Half of the works of miniaturized imprinted monoliths is as stationary phase in separation techniques such as in CEC and to a lesser extent in nanoLC. The monolithic MIPs in devices dedicated to separation purposes have a diameter ranging from 25 to $320 \mu \mathrm{m}$ with a majority at $100 \mu \mathrm{m}$ and their lengths fluctuate between 4 and $100 \mathrm{~cm}$, which represent phase volumes ranging from $25 \mathrm{~nL}$ to $4 \mu \mathrm{L}$ (Table 6). As visible in this table, a large number of publications indicated that they are particularly effective for the separation of enantiomers $[75,76,79,83,88-90,98,102,108,111,112]$ and structural analogues $[39,78,88,91,92,96,97,100,101,109]$. For the enantiomeric separation, the resolution can be used in the same way as for the open tubular approach to highlight the contribution of the specific cavities. For the separation of structural analogs, the criterion that best reflects the MIP performance in CEC or nanoLC is the imprinting factor (IF) $[78,91,94,96-101,109,110]$, that is defined as the ratio of the retention factors $k$ of a compound on the MIP and NIP phases (IF $=k_{\text {MIP }} / k_{\text {NIP }}$ with $k=\left(t_{r}-t_{0}\right) / t_{0}$ where $t_{r}$ is the retention time of the compound and $t_{0}$ the retention time of a non-retained compound). It is also essential to pay attention to other figures of merit of the method, i.e. its repeatability whatever the synthesis or the separation, and the lifetime of the columns.

Schweitz et al. [90] were the first to perform a chiral separation with a monolithic MIP in a capillary of $75 \mu \mathrm{m}$ i.d.. An optimal ratio of monomers, template, and porogen solvent was determined to obtain a monolithic MIP possessing good flow-through characteristics, then, $\mathrm{pH}$ and organic solvent content of the mobile phase were optimized to separate $\mathrm{R}$ - and $\mathrm{S}$ ropivacaine. However, no $R_{s}$ was provided. The highest $R_{s}$ value was reported by Wang et al. [102] for the separation of R,S-naproxen with a resolution of 8.82 obtained with a MIP prepared by adding a ionic liquid in the porogen.

Two different stationary phases were developed by Ou et al. for the CEC separation of tetrahydropalmatine or Tröger's base, either an organic monolithic MIP [89] or an organic MIP layer on a silica-based core monolith [108]. The enantioseparation was achieved within 4 min with both MIPs but the MIP prepared on the silica-based core monolith led to the best column efficiency and stability. In addition, the column-to-column and batch-to-batch repeatability was studied on retention times and EOF and RSD values $(n=3)$ lower than $8 \%$ were obtained. A MIP synthesized at the surface of a poly(TRIM) monolith was used for the CEC enantioseparation of amlodipine [111]. After having studied the influence of parameters such as the mobile phase composition, its $\mathrm{pH}$ value, and operating voltages, a strong recognition ability was obtained with a selectivity of 5.83 and a resolution of 7.99 . The batch-to-batch RSDs $(n=3)$ for the retention time, column efficiency, and resolution were $1.67,4.75$, and $3.61 \%$, respectively.

Among the different works reported on the separation of structural analogues, one of them was done in the field of pesticides with an hybrid organic-inorganic monolithic MIP imprinted with carbaryl [101]. Three carbamates (carbaryl, fenobucarb, and metolcarb) were separated by CEC and led to IF of $7.57,1.27$, and 1.64 , respectively. RSD values $(n=3)$ for retention times 
lower than $2.1 \%$ and $4.5 \%$ for the run-to-run and the column-to-column repeatability, respectively, were measured.

Miniaturized imprinted monoliths were also applied to separate biological macromolecules. For example, Zheng et al. [91] studied the selective retention in CEC of nonapeptide oxytocin based on the epitope approach with a monolithic MIP synthesized using the tetrapeptide YPLG (Tyrosine-Proline-Leucine-Glycine) as template. This pseudo-dummy approach allowed to obtain a template soluble in the synthesis medium. By optimizing the polymerization mixture, a good selectivity was obtained for oxytocin with an IF of 4.01 and a column efficiency of 16,952 plates $\mathrm{m}^{-1}$ was achieved. To further investigate the MIP selectivity, a mixture of oxytocin and proteins including BSA, bovine hemoglobin, ovalbumin, and lysozyme was analyzed. All proteins were co-eluted except oxytocin. A separation factor, defined as the ratio of the retention times of the oxytocin peak to that of the co-eluted compounds, of 4.45 was obtained on MIP in opposition to 2.33 on NIP, demonstrating the selectivity of such support. It is possible to take advantage of the MIP selectivity to determine a single compound present in a complex sample containing other analytes. For example, a hybrid organic-inorganic monolithic MIP was used for the determination by CEC-UV of traces of trichlorfon in vegetable extracts with a limit of quantification (LOQ, based on a signal-to-noise ratio of 10) of 305.3 $\mu \mathrm{g} \mathrm{kg}{ }^{-1}$ [104]. Another example relies on the quantification of thiabendazole in citrus extracts in CEC-UV with an LOQ of $0.14 \mathrm{mg} \mathrm{kg}^{-1}$, i.e. below the established maximum residue limits for control of this fungicide[84].

Enantioseparation and separation of structural analogs can also be achieved simultaneously. Indeed, an organic monolith imprinted with (-)-norepinephrine allowed the CEC separation of six neurotransmitters and their enantiomers including dopamine, epinephrine, isoproterenol, octapamine, synephrine, and norepinephrine [112]. In pure medium, an average separation efficiency of 98,000 plates $\mathrm{m}^{-1}$ was calculated and stability tests established that separation was still achieved after 2 months and more than 600 injections. CEC was also performed for spiked urine samples and neurotransmitters were still separated but the salts present in urine reduced drastically the chiral separation of all the analytes and only the template, norepinephrine, was enantioseparated.

The synthesis of monolithic MIPs in capillaries was a significant progress in miniaturization. Another objective is their integration into a $\mu$-TAS. In this context, a hybrid microsystem was described, based on the introduction of a capillary containing the MIP into a chip [77]. This portable device applied to the CEC enantioseparation of D,L-tyrosine consists of a capillary of $25 \mu \mathrm{m}$ i.d. and $5 \mathrm{~cm}$ long containing a poly(AA-co-EGDMA) polymer imprinted with L-tyrosine and coupled to a carbon fiber microdisk working electrode for amperometric detection. A resolution of 2.40 was achieved within $55 \mathrm{~s}$ with RSDs $(n=6)$ for retention time and peak area of 1.2-1.4 and 2.4-2.8\% for run-to-run, 2.3-2.4 and 4.3-5.1\% for day-to-day, and 3.2-4.2 and 5.8-6.8\% for chip-to-chip, respectively, suggesting a good stability of MIP, but also that the MIP-based chips have a good manufacturing reproducibility. It can be noticed that the open tubular approach proposed by the same author for CEC enantioseparation led to lower separation performances for the same targets due to the low volume of MIP stationary phase in the capillary with a resolution of 1.02 for the enantioseparation of D, L-tyrosine [45].

Imprinted monoliths were also used in nanoLC [94,99,108-110]. Three supports were synthesized with different templates including bupivacaine, mepivacaine, and S-ropivacaine [109]. Very encouraging IFs were obtained $(29,14$, and 43 , respectively) with low retention on the monolithic NIP. However, the difficulties for authors in determining to makes the 
uncertainty of this parameter relatively large. IFs were calculated based on the center of gravity of the peaks, it is therefore necessary to put the results into perspective.

\subsection{Monolithic molecularly imprinted polymers in extraction}

The monolithic approach for selective extraction in capillaries or channels is the most widely reported one, because of its advantages in terms of phase quantity compared to the open tubular MIPs, and of ease of preparation and higher homogeneity compared to packing of MIP particles.

\subsubsection{Molecularly imprinted polymers in capillaries}

Miniaturized monolithic MIPs synthesized in capillaries were used for extraction of various targets such as drugs $[73,86,93,95,105]$, biomarkers [35-37], proteins [94,99], dyes [80,82,85], fungicides [107], or toxins [38,40] in different complex matrices including urine [35-37], saliva [86], food [38,73,80,82,85,93,105,107], plants [95], or serum [86,94,99] (Table 7).

Although being an important parameter in extraction, binding capacities calculated at miniaturized scale are difficult to compare because they are not expressed in the same unit

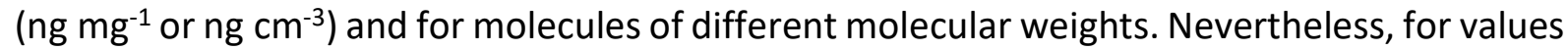
expressed in the same unit, most values are between 60 and 4,000 $\mathrm{ng} \mathrm{mg}^{-1}$. To improve this capacity, new approaches of synthesis were recently described [38,103,105-107]. As an example, carbon quantum dots [38], multi-walled carbon nanotubes [107], silanized graphene oxide (SGO) [105,106], and silver-modified graphene oxide [103] were introduced in the polymerization mixture to improve the specific surface areas. The use of acryloyl- $\beta$ cyclodextrin with MAA as dual-functional monomers was also proposed to improve the adsorption capacities of the MIP for thiabendazole [107]. SGO was also combined with a metal ion, $\mathrm{Zn}^{2+}$, to stabilize the template-monomer complex before the polymerization thus allowing a higher adsorption capacity of the resulting MIP [105]. POSS, i.e. nano-building blocks with cage like architecture containing silicon and oxygen, was also proposed with EGDMA as cocross-linkers and VP as monomer to get a hybrid monolithic MIP for baicalin with reinforced physical properties and enhanced adsorption capacity [95].

Most of the reported applications deal with sample extracts diluted in solvents similar to the porogen used for the synthesis and thus adapted to develop the appropriate interactions between the target compounds and the cavities. The selectivity can be checked, as previously mentioned, by studying the behavior of the target analyte(s) in parallel on the NIP, the ratio of retention factors $\mathrm{k}$ between both sorbents allowing to calculate the IF. Values between 2.2 and 3.4 were reported $[40,73,86,95]$.

As shown in Table 7, most of the published works reported monolithic MIPs synthesized in 3.5-10 cm length and 500-530 $\mu \mathrm{m}$ i.d. capillaries that were off-line used before conventional LC analysis (4.6 $\mathrm{mm}$ i.d. column) $[35,38,73,82,85,105,107]$. The percolated volumes ranged from 1 to $8 \mathrm{~mL}$ and are therefore close to volumes percolated on SPE cartridges to obtain sufficient EF and enough sensitivity in LC. For example, Zheng et al. developed a monolith imprinted with pefloxacin for the selective extraction of four fluoroquinolones from milk samples [73]. The selectivity was demonstrated as an IF of 3.1 was determined by LC measurements for the template. It was also demonstrated by calculating the ratio of extraction recoveries between MIP and NIP for pefloxacin and the four other fluoroquinolones and values between 1.7 and 3.6 were obtained in pure medium. To highlight the performance 
of the monolithic MIP, extractions with a spiked milk sample on the miniaturized monolithic MIP and a C18 sorbent in a SPE cartridge were compared. While no interference was observed after the extraction on the MIP, several interfering peaks were observed after extraction on C18 due to non-specific interactions. For a monolithic MIP prepared in a capillary for the selective extraction of safranin T in wolfberry further analyzed by LC-LIF a recovery of $80.7 \%$ was obtained on the MIP compared to $23.4 \%$ on the NIP in pure medium [82] and an EF higher than 90 was calculated with a wolfberry sample by comparing chromatograms obtained before and after its extraction on MIP.

Monolithic MIPs in capillary with high i.d. dimensions (500 or $530 \mu \mathrm{m}$ ) were reported for an off-line used with CE analysis, allowing to achieve both extraction and separation steps at miniaturized scale $[37,80]$. Monolithic MIPs synthesized in capillaries with smaller i.d. (75$100 \mu \mathrm{m})$ but very long $(25 \mathrm{~cm})$ were also applied for extraction of biological macromolecules before off-line SDS-PAGE analyses [94,99]. These monolithic MIPs were imprinted with horseradish peroxidase (45 kDa) [99] or lysozyme (14.4 kDa) [94] and applied to the extraction of the target proteins from spiked human sera diluted 500 times.

As indicated in Table 7, another significant part of the studies focused on the on-line coupling of the MIP extraction with conventional LC separation columns $(4.6 \mathrm{~mm}[36,93,95]$ or $2.1 \mathrm{~mm}$ [74] i.d.). In these cases, the general trend is towards a reduction of the i.d. of the capillary containing the monolithic MIP compared with the ones used for off-line applications, with i.d. values between 250 and $500 \mu \mathrm{m}$ and with lengths between 10 and $25 \mathrm{~cm}$. For example, Zhang et al. achieved trace analysis of antimicrobials (sulfaquinoxaline, sulfametoxydiazine, sulfamethoxazole, mequindox, and quinocetone) in chicken, pork, and egg samples with a monolithic MIP imprinted with sulfaquinoxaline in a $12 \mathrm{~cm} \times 320 \mu \mathrm{m}$ capillary coupled on-line to LC-UV [93]. The selectivity was demonstrated by a ratio of extraction recoveries on MIP and NIP between 1.8 and 4.3 for the five studied compounds contained in pure medium.

Szumski et al. were the first to propose an on-line miniaturized set-up by coupling a MIP prepared in a $100 \mu \mathrm{m}$ i.d. capillary with a $180 \mu \mathrm{m}$ i.d. analytical column for the nanoLC-LIF analysis of four aflatoxins $\left(B_{1}, B_{2}, G_{1}\right.$, and $\left.G_{2}\right)$ [40]. With the injection of $5 \mu \mathrm{L}$ of a model solution of four aflatoxins, the signal of the analytes was detected during the percolation step on the NIP, while the majority of these analytes was observed after the separation step when the MIP was used thus highlighting the selective contribution of the MIP in a pure medium.

Concerning real sample application with this kind of miniaturized set-up, a work was recently conducted on a monolithic MIP imprinted with cocaine in a $100 \mu \mathrm{m}$ i.d. capillary and coupled on-line to a $75 \mu \mathrm{m}$ i.d. nanoLC column (Figure 3) [86]. The selectivity of the MIP was first demonstrated by obtaining IF values of $3.2 \pm 0.5$ and $2.2 \pm 0.3 \quad(n=3)$ by nanoLC measurements for cocaine and its main metabolite (benzoylecgonine), respectively, in pure media. After a careful optimization of the washing step implying the use of NIP in parallel to the MIP to control the non-retention on the NIP, cocaine was determined in biological fluids, i.e. plasma and saliva. Figure $\mathbf{3}$ presents the chromatograms obtained with spiked or blank saliva or plasma samples. The very low retention on NIP confirms IF values measured in pure media. The very clean-baseline obtained using the MIP allows the easy determination of the cocaine with UV detection with a LOQ of 6.1 and $14.5 \mathrm{ng} \mathrm{mL}^{-1}$ while injecting only $100 \mathrm{~nL}$ of saliva or 2 times diluted plasma, respectively. Such small volumes illustrate the excellent sensitivity of the miniaturized analytical system.

Finally, Wen et al. proposed a simplified device by directly coupling the MIP to UV without any separation step [113]. The MIP was able to selectively capture and release myoglobin from $1 \mu \mathrm{L}$ of a protein mixture in water containing myoglobin $\left(1 \mathrm{mg} \mathrm{mL}^{-1}\right)$, lysozyme $\left(0.5 \mathrm{mg} \mathrm{mL}^{-1}\right)$, 
and bovine serum albumin $\left(0.5 \mathrm{mg} \mathrm{mL}^{-1}\right)$. The retention behavior of the MIP was controlled by temperature, which induces a change in solvation, due to the temperature-responsive properties of the poly(N-isopropylacrylamide) constituting the MIP. However, there is no quantitative data on the extraction recoveries and no applications with real samples.

The study of the repeatability of the MIP syntheses and analytical methods was very often omitted by the authors. When it was the case, most of the publications implemented the intraand inter-day study on recoveries $[36,38,73,80,82,105,107]$. The reproducibility of the synthesis was rarely reported and consisted in comparing the results of the recoveries obtained in pure medium with MIPs from different batches and without giving any data for the NIPs $[35,73,93,95]$. Only two publications investigated the repeatability by comparing recoveries obtained with plasma samples and independently synthesized MIPs in capillaries $[74,86]$. The first one measured the permeability and IFs for independently synthesized MIPs with RSD $(n=3)$ of 3-17\% [86], and the second one measured the adsorption capacities for independently synthesized MIPs and NIPs with RSDs $(n=3)$ of $2.3-5.0 \%$ [38]. At last, in order to reduce the analytical cost, the reusability of some MIPs was evaluated showing the possibility to use them at least 15 [38], 20 [107], 50 [35,73,74], or 100 times [93] with no significant changes in column backpressure and extraction efficiency, although these studies were conducted in pure medium.

\subsubsection{Molecularly imprinted polymers in chip microchannels}

To date, as for their application in separation, only attempts to integrate monolithic MIPs by hybrid approaches, i.e. by introducing a capillary containing a MIP in a chip, were described in the literature $[81,103,106]$. A first hybrid approach consists in introducing a capillary $(2.7 \mathrm{~cm}$ $x 500 \mu \mathrm{m}$ i.d.) containing a monolithic MIP into a glass/PDMS device that also contains a separation microchannel of $75 \mu \mathrm{m}$ deep and $100 \mu \mathrm{m}$ wide for on-line SPE-CE and conductivity detection. It was applied to the determination of auramine $O$ in spiked shrimp extracts [81]. An EF of 12 was determined for an injection of $440 \mu \mathrm{L}$ of a standard solution, but these results were given for off-line mode and unfortunately not for the on-line one. In addition, the concentration of the spiked extracts was of $5 \mu \mathrm{g} \mathrm{mL}{ }^{-1}$, which is high.

This pioneer work dealing with a MIP involved in an on-line SPE-CE on chip was followed by two other works reported by the same group based again on broad capillaries of $500 \mu \mathrm{m}$ i.d. used to selectively extract compounds from large samples of $8 \mathrm{~mL}$ before their off-line analysis in LC $[103,106]$. These devices integrate four [106] or eight [103] MIP capillaries (3.5-4 cm x $500 \mu \mathrm{m}$ i.d.) in parallel in a chip for the simultaneous determination of bisphenol A and nonyl phenol in spiked fish sample extracts [103] or rhodamine B from chili powder extracts [106]. RSD on recoveries between 3.4 and $4.1 \%$ were obtained for chip-to-chips $[103,106]$ and each MIP or chip could be reused at least 15 [103] or 30 times [106]. In both cases, the eluted fractions were analyzed off-chip by LC-FLD. Therefore, many efforts remain to be made for the development of chips integrating MIP extraction, separation, and detection steps with an on-line mode, as it was the original purpose of the concept of $\mu$-TAS. If the MIP selectivity is really high, one could even consider removing the separation step and thus simplify the chip device by only integrating the detection device.

\section{Conclusions and perspectives}


The current analytical chemistry literature is rich in works on miniaturized devices to meet the societal demand for reliable, fast, inexpensive, and low solvent/sample consuming analyses. All the steps of the analysis must be redesigned and the development of miniaturized selective sorbents such as MIPs is therefore essential for both extraction and separation applications. Various methods allowing the miniaturization of MIPs were referenced such as open tubular, packed particles, magnetic nanoparticles, and of course in situ synthesis of imprinted monoliths, which in the light of the diversity of applications proposed in this review seems to be the most completely developed approach.

Throughout the review, we highlighted the diversity of approaches leading to the preparation of monolithic MIP in capillaries or in chip microchannels with different combinations of templates, monomers, cross-linkers, and porogen solvents. The targets are of various natures and range from small molecules to glycoproteins. These devices have demonstrated great potential for separation and extraction applications. For the latter area, a significant progress has been made by the authors by having carried out applications with real samples such as biological, environmental, and food ones, although it appears that development in pure medium still concerns the majority of publications. However, the main aspect to be improved is the description of the repeatability of the syntheses and the lifetime of the systems, particularly when applying real samples, which are characteristics that have been insufficiently studied.

Further developments of in situ MIPs synthesized in capillaries can undoubtedly be expected. This approach is particularly interesting in view of the development of coupling all the stages of analysis and tending towards lab-on-chip type systems. In the context of these developments, the high selectivity generated by the MIP is an obvious advantage. It allows a lower resolution requirement of the separation systems, whose length can be greatly reduced, and even allows to move towards systems where the MIP used as a support for selective concentration or retention will require just downstream the integration of a detection step.

The authors have declared no conflict of interest. 


\section{References}

[1] Delaunay, N., Combès, A., Pichon, V., Immunoaffinity Extraction and Alternative Approaches for the Analysis of Toxins in Environmental, Food or Biological Matrices. Toxins 2020, 12, 795.

[2] Luliński, P., Molecularly imprinted polymers based drug delivery devices: a way to application in modern pharmacotherapy. A review. Mater. Sci. Eng. C 2017, 76, 1344-1353.

[3] Piletsky, S., Canfarotta, F., Poma, A., Bossi, A. M., Piletsky, S., Molecularly imprinted polymers for cell recognition. Trends Biotechnol. 2019, 38, 368-387.

[4] Tuwahatu, C. A., Yeung, C. C., Lam, Y. W., Roy, V. A. L., The molecularly imprinted polymer essentials: Curation of anticancer, ophthalmic, and projected gene therapy drug delivery systems. J. Controlled Release 2018, 287, 24-34.

[5] Cao, Y., Feng, T., Xu, J., Xue, C., Recent advances of molecularly imprinted polymer-based sensors in the detection of food safety hazard factors. Biosens. Bioelectron. 2019, 141, 111447.

[6] Saylan, Y., Akgönüllü, S., Yavuz, H., Ünal, S., Denizli, A., Molecularly imprinted polymer based sensors for medical applications. Sensors 2019, 19, 1279.

[7] Ahmad, O. S., Bedwell, T. S., Esen, C., Garcia-Cruz, A., Piletsky, S. A., Molecularly imprinted polymers in electrochemical and optical sensors. Trends Biotechnol. 2019, 37, 294-309.

[8] BelBruno, J. J., Molecularly imprinted polymers. Chem. Rev. 2019, 119, 94-119.

[9] Yin, Y., Dong, Z., Luo, Q., Liu, J., Biomimetic catalysts designed on macromolecular scaffolds. Prog. Polym. Sci. 2012, 37, 1476-1509.

[10] Wei, Z.-H., Mu, L.-N., Huang, Y.-P., Liu, Z.-S., Imprinted monoliths: Recent significant progress in analysis field. TrAC Trends Anal. Chem. 2017, 86, 84-92.

[11] Cheong, W. J., Ali, F., Choi, J. H., Lee, J. O., Yune Sung, K., Recent applications of molecular imprinted polymers for enantio-selective recognition. Talanta 2013, 106, 45-59.

[12] Zheng, C., Huang, Y.-P., Liu, Z.-S., Synthesis and theoretical study of molecularly imprinted monoliths for HPLC. Anal. Bioanal. Chem. 2013, 405, 2147-2161.

[13] lacob, B. C., Bodoki, E., Oprean, R., Recent advances in capillary electrochromatography using molecularly imprinted polymers: CE and CEC. Electrophoresis 2014, 35, 2722-2732.

[14] Mu, L.-N., Wei, Z.-H., Liu, Z.-S., Current trends in the development of molecularly imprinted polymers in CEC: CE and CEC. Electrophoresis 2015, 36, 764-772.

[15] Rutkowska, M., Płotka-Wasylka, J., Morrison, C., Wieczorek, P. P., Namieśnik, J., Marć, M., Application of molecularly imprinted polymers in analytical chiral separations and analysis. TrAC Trends Anal. Chem. 2018, 102, 91-102.

[16] Xu, X., Zhu, L., Chen, L., Separation and screening of compounds of biological origin using molecularly imprinted polymers. J. Chromatogr. B 2004, 804, 61-69.

[17] Pichon, V., Delaunay, N., Combes, A., Sample preparation using molecularly imprinted polymers. Anal. Chem. 2020, 92, 16-33.

[18] Gama, M. R., Bottoli, C. B. G., Molecularly imprinted polymers for bioanalytical sample preparation. J. Chromatogr. B 2017, 1043, 107-121.

[19] Pichon, V., Chapuis-Hugon, F., Role of molecularly imprinted polymers for selective determination of environmental pollutants-A review. Anal. Chim. Acta 2008, 622, 48-61.

[20] Beltran, A., Borrull, F., Marcé, R. M., Cormack, P. A. G., Molecularly-imprinted polymers: Useful sorbents for selective extractions. TrAC Trends Anal. Chem. 2010, 29, 1363-1375.

[21] Farooq, S., Nie, J., Cheng, Y., Yan, Z., Li, J., Bacha, S. A. S., Mushtaq, A., Zhang, H., Molecularly imprinted polymers' application in pesticide residue detection. Analyst 2018, 143, 3971-3989.

[22] Ndunda, E. N., Mizaikoff, B., Molecularly imprinted polymers for the analysis and removal of polychlorinated aromatic compounds in the environment: A review. Analyst 2016, 141, 31413156.

[23] Boulanouar, S., Mezzache, S., Combès, A., Pichon, V., Molecularly imprinted polymers for the determination of organophosphorus pesticides in complex samples. Talanta 2018, 176, 465478. 
[24] Chen, L., Wang, X., Lu, W., Wu, X., Li, J., Molecular imprinting: perspectives and applications. Chem. Soc. Rev. 2016, 45, 2137-2211.

[25] Hu, T., Chen, R., Wang, Q., He, C., Liu, S., Recent advances and applications of molecularly imprinted polymers in solid-phase extraction for real sample analysis. J. Sep. Sci. 2020, DOI: 10.1002/jssc.202000832.

[26] Arabi, M., Ostovan, A., Bagheri, A. R., Guo, X., Wang, L., Li, J., Wang, X., Li, B., Chen, L., Strategies of molecular imprinting-based solid-phase extraction prior to chromatographic analysis. TrAC Trends Anal. Chem. 2020, 128, 115923.

[27] Boysen, R. I., Advances in the development of molecularly imprinted polymers for the separation and analysis of proteins with liquid chromatography. J. Sep. Sci. 2019, 42, 51-71.

[28] Xing, R., Wen, Y., He, H., Guo, Z., Liu, Z., Recent progress in the combination of molecularly imprinted polymer-based affinity extraction and mass spectrometry for targeted proteomic analysis. TrAC Trends Anal. Chem. 2019, 110, 417-428.

[29] Ansari, S., Masoum, S., Molecularly imprinted polymers for capturing and sensing proteins: Current progress and future implications. TrAC Trends Anal. Chem. 2019, 114, 29-47.

[30] Jia, M., Zhang, Z., Li, J., Ma, X., Chen, L., Yang, X., Molecular imprinting technology for microorganism analysis. TrAC Trends Anal. Chem. 2018, 106, 190-201.

[31] Matsui, Jun., Kato, Teru., Takeuchi, Toshifumi., Suzuki, Masayasu., Yokoyama, Kenji., Tamiya, Eiichi., Karube, Isao., Molecular recognition in continuous polymer rods prepared by a molecular imprinting technique. Anal. Chem. 1993, 65, 2223-2224.

[32] Reyes, D. R., lossifidis, D., Auroux, P.-A., Manz, A., Micro Total analysis systems. 1. Introduction, theory, and technology. Anal. Chem. 2002, 74, 2623-2636.

[33] Manz, A., Graber, N., Widmer, H. M., Miniaturized total chemical analysis systems: A novel concept for chemical sensing. Sens. Actuators B Chem. 1990, 1, 244-248.

[34] Masini, J. C., Svec, F., Porous monoliths for on-line sample preparation: A review. Anal. Chim. Acta 2017, 964, 24-44.

[35] Zhang, S. W., Xing, J., Cai, L. S., Wu, C. Y., Molecularly imprinted monolith in-tube solid-phase microextraction coupled with HPLC/UV detection for determination of 8-hydroxy-2'deoxyguanosine in urine. Anal. Bioanal. Chem. 2009, 395, 479-487.

[36] Zhang, S., Sun, X., Wang, W., Cai, L., Determination of urinary 8-hydroxy-2'-deoxyguanosine by a combination of on-line molecularly imprinted monolithic solid phase microextraction with high performance liquid chromatography-ultraviolet detection: Sample Preparation. J. Sep. Sci. 2013, 36, 752-757.

[37] Zhang, S., Song, X., Zhang, W., Luo, N., Cai, L., Determination of low urinary 8-hydroxy-2'deoxyguanosine excretion with capillary electrophoresis and molecularly imprinted monolith solid phase microextraction. Sci. Total Environ. 2013, 450-451, 266-270.

[38] Liang, G., Zhai, H., Huang, L., Tan, X., Zhou, Q., Yu, X., Lin, H., Synthesis of carbon quantum dotsdoped dummy molecularly imprinted polymer monolithic column for selective enrichment and analysis of aflatoxin B1 in peanut. J. Pharm. Biomed. Anal. 2018, 149, 258-264.

[39] Wang, Q., Zhang, X., Li, J., Xu, Z., Synthesis and evaluation of organic-inorganic hybrid molecularly imprinted monolith column for selective recognition of acephate and phosphamidon in vegetables. Adv. Polym. Technol. 2015, 36, 401-408.

[40] Szumski, M., Grzywiński, D., Prus, W., Buszewski, B., Monolithic molecularly imprinted polymeric capillary columns for isolation of aflatoxins. J. Chromatogr. A 2014, 1364, 163-170.

[41] Brüggemann, O., Freitag, R., Whitcombe, M. J., Vulfson, E. N., Comparison of polymer coatings of capillaries for capillary electrophoresis with respect to their applicability to molecular imprinting and electrochromatography. J. Chromatogr. A 1997, 781, 43-53.

[42] Tan, Z. J., Remcho, V. T., Molecular imprint polymers as highly selective stationary phases for open tubular liquid chromatography and capillary electrochromatography. Electrophoresis 1998, 19, 2055-2060. 
[43] Qu, P., Lei, J., Ouyang, R., Ju, H., Enantioseparation and amperometric detection of chiral compounds by in situ molecular imprinting on the microchannel wall. Anal. Chem. 2009, 81, 9651-9656.

[44] Zaidi, S. A., Cheong, W. J., Long open tubular molecule imprinted polymer capillary columns with excellent separation efficiencies in chiral and non-chiral separation by capillary electrochromatography. Electrophoresis 2009, 30, 1603-1607.

[45] Qu, P., Lei, J., Sheng, J., Zhang, L., Ju, H., Simultaneous multiple enantioseparation with a onepot imprinted microfluidic channel by microchip capillary electrochromatography. The Analyst 2011, 136, 920-926.

[46] Zaidi, S. A., Cheong, W. J., Preparation of an open-tubular capillary column with a monolithic layer of S-ketoprofen imprinted and 4-styrenesulfonic acid incorporated polymer and its enhanced chiral separation performance in capillary electrochromatography. J. Chromatogr. A 2009, 1216, 2947-2952.

[47] Jang, R., Kim, K. H., Zaidi, S. A., Cheong, W. J., Moon, M. H., Analysis of phospholipids using an open-tubular capillary column with a monolithic layer of molecularly imprinted polymer in capillary electrochromatography-electrospray ionization-tandem mass spectrometry. Electrophoresis 2011, 32, 2167-2173.

[48] Kulsing, C., Knob, R., Macka, M., Junor, P., Boysen, R. I., Hearn, M. T. W., Molecular imprinted polymeric porous layers in open tubular capillaries for chiral separations. J. Chromatogr. A 2014, 1354, 85-91.

[49] Huang, Y.-C., Lin, C.-C., Liu, C.-Y., Preparation and evaluation of molecularly imprinted polymers based on 9-ethyladenine for the recognition of nucleotide bases in capillary electrochromatography. Electrophoresis 2004, 25, 554-561.

[50] Zhao, Q.-L., Zhou, J., Zhang, L.-S., Huang, Y.-P., Liu, Z.-S., Coatings of molecularly imprinted polymers based on polyhedral oligomeric silsesquioxane for open tubular capillary electrochromatography. Talanta 2016, 152, 277-282.

[51] Song, W.-F., Zhao, Q.-L., Zhou, X.-J., Zhang, L.-S., Huang, Y.-P., Liu, Z.-S., A star-shaped molecularly imprinted polymer derived from polyhedral oligomeric silsesquioxanes with improved site accessibility and capacity for enantiomeric separation via capillary electrochromatography. Microchim. Acta 2019, 186, 1-7.

[52] Wu, X., Wei, Z.-H., Huang, Y.-P., Liu, Z.-S., Preparation of molecularly imprinted coatings with ternary porogen for CEC. Chromatographia 2010, 72, 101-109.

[53] Zhang, X., Xu, S., Lee, Y.-I., Soper, S. A., LED-induced in-column molecular imprinting for solid phase extraction/capillary electrophoresis. The Analyst 2013, 138, 2821.

[54] Zhang, X., Zhu, D., Huang, C., Sun, Y., Lee, Y.-I., Sensitive detection of bisphenol A in complex samples by in-column molecularly imprinted solid-phase extraction coupled with capillary electrophoresis. Microchem. J. 2015, 121, 1-5.

[55] Schweitz, L., Molecularly imprinted polymer coatings for open-tubular capillary electrochromatography prepared by surface initiation. Anal. Chem. 2002, 74, 1192-1196.

[56] Lin, J.-M., Nakagama, T., Uchiyama, K., Hobo, T., Enantioseparation of D,L-phenylalanine by molecularly imprinted polymer particles filled capillary electrochromatography. J. Liq. Chromatogr. Relat. Technol. 1997, 20, 1489-1506.

[57] Lara, F. J., Lynen, F., Sandra, P., García-Campaña, A. M., Alés-Barrero, F., Evaluation of a molecularly imprinted polymer as in-line concentrator in capillary electrophoresis. Electrophoresis 2008, 29, 3834-3841.

[58] Moreno-González, D., Lara, F. J., Gámiz-Gracia, L., García-Campaña, A. M., Molecularly imprinted polymer as in-line concentrator in capillary electrophoresis coupled with mass spectrometry for the determination of quinolones in bovine milk samples. J. Chromatogr. A 2014, 1360, 1-8.

[59] He, D., Zhang, Z., Zhou, H., Huang, Y., Micro flow sensor on a chip for the determination of terbutaline in human serum based on chemiluminescence and a molecularly imprinted polymer. Talanta 2006, 69, 1215-1220. 
[60] Lei, J. D., Tong, A. J., Preparation of Z-L-Phe-OH-NBD imprinted microchannel and its molecular recognition study. Spectrochim. Acta. A. Mol. Biomol. Spectrosc. 2005, 61, 1029-1033.

[61] Azizi, A., Bottaro, C. S., A critical review of molecularly imprinted polymers for the analysis of organic pollutants in environmental water samples. J. Chromatogr. A 2020, 1614, 460603.

[62] Ansari, S., Karimi, M., Recent configurations and progressive uses of magnetic molecularly imprinted polymers for drug analysis. Talanta 2017, 167, 470-485.

[63] Wang, X. N., Liang, R. P., Meng, X. Y., Qiu, J. D., One-step synthesis of mussel-inspired molecularly imprinted magnetic polymer as stationary phase for chip-based open tubular capillary electrochromatography enantioseparation. J. Chromatogr. A 2014, 1362, 301-308.

[64] Chen, J., Liang, R. P., Wang, X. N., Qiu, J. D., A norepinephrine coated magnetic molecularly imprinted polymer for simultaneous multiple chiral recognition. J. Chromatogr. A 2015, 1409, 268-276.

[65] Wu, L.-L., Liang, R.-P., Chen, J., Qiu, J.-D., Separation of chiral compounds using magnetic molecularly imprinted polymer nanoparticles as stationary phase by microchip capillary electrochromatography. Electrophoresis 2018, 39, 356-362.

[66] Qu, P., Lei, J., Zhang, L., Ouyang, R., Ju, H., Molecularly imprinted magnetic nanoparticles as tunable stationary phase located in microfluidic channel for enantioseparation. J. Chromatogr. A 2010, 1217, 6115-6121.

[67] Ou, J., Kong, L., Pan, C., Su, X., Lei, X., Zou, H., Determination of D,L-tetrahydropalmatine in Corydalis yanhusuo by L-tetrahydropalmatine imprinted monolithic column coupling with reversed-phase high performance liquid chromatography. J. Chromatogr. A 2006, 1117, 163169.

[68] Ou, J., Hu, L., Hu, L., Li, X., Zou, H., Determination of phenolic compounds in river water with on-line coupling bisphenol A imprinted monolithic precolumn with high performance liquid chromatography. Talanta 2006, 69, 1001-1006.

[69] Wang, S., Li, D., Hua, Z., Zhao, M., Molecularly imprinted monolith coupled on-line with high performance liquid chromatography for simultaneous quantitative determination of cyromazine and melamine. The Analyst 2011, 136, 3672.

[70] Javanbakht, M., Moein, M. M., Akbari-adergani, B., On-line clean-up and determination of tramadol in human plasma and urine samples using molecularly imprinted monolithic column coupling with HPLC. J. Chromatogr. B 2012, 911, 49-54.

[71] Lv, Y. K., Yang, L., Liu, X. H., Guo, Z. Y., Sun, H. W., Preparation and evaluation of a novel molecularly imprinted hybrid composite monolithic column for on-line solid-phase extraction coupled with HPLC to detect trace fluoroquinolone residues in milk. Anal. Methods 2013, 5, 1848.

[72] Li, X., Zhou, M., Turson, M., Lin, S., Jiang, P., Dong, X., Preparation of clenbuterol imprinted monolithic polymer with hydrophilic outer layers by reversible addition-fragmentation chain transfer radical polymerization and its application in the clenbuterol determination from human serum by on-line solid-phase extraction/HPLC analysis. The Analyst 2013, 138, 3066-3074.

[73] Zheng, M. M., Gong, R., Zhao, X., Feng, Y.-Q., Selective sample pretreatment by molecularly imprinted polymer monolith for the analysis of fluoroquinolones from milk samples. $J$. Chromatogr. A 2010, 1217, 2075-2081.

[74] Marchioni, C., Vieira, T. M., Miller Crotti, A. E., Crippa, J. A., Costa Queiroz, M. E., In-tube solidphase microextraction with a dummy molecularly imprinted monolithic capillary coupled to ultra-performance liquid chromatography-tandem mass spectrometry to determine cannabinoids in plasma samples. Anal. Chim. Acta 2020, 1099, 145-154.

[75] Liao, S., Wang, X., Lin, X., Wu, X., Xie, Z., A molecularly imprinted monolith for the fast chiral separation of antiparasitic drugs by pressurized CEC. J. Sep. Sci. 2010, 33, 2123-2130.

[76] He, J., Fang, G., Deng, Q., Wang, S., Preparation, characterization and application of organicinorganic hybrid ractopamine multi-template molecularly imprinted capillary monolithic column. Anal. Chim. Acta 2011, 692, 57-62. 
[77] Qu, P., Zhang, L., Sheng, J., Lei, J., Ju, H., Convenient enantioseparation by monolithic imprinted capillary clamped in a chip with electrochemical detection. Electrophoresis 2011, 32, 15221529.

[78] Zaidi, S. A., Dual-templates molecularly imprinted monolithic columns for the evaluation of serotonin and histamine in CEC: CE and CEC. Electrophoresis 2013, 34, 1375-1382.

[79] Li, M., Lin, X., Xie, Z., Investigation of enantiomer recognition of molecularly imprinted polymeric monoliths in pressurized capillary electrochromatography screening the amino acids and their derivatives. J. Chromatogr. A 2009, 1216, 5320-5326.

[80] Yuan, K., Wang, J., Zhai, H., Chen, Z., Huang, L., Su, Z., Sensitive determination of rose bengal in brown sugar by a molecularly imprinted solid-phase extraction monolithic capillary column coupled with capillary electrophoresis. Anal Methods 2015, 7, 8297-8303.

[81] Zhai, H., Li, J., Chen, Z., Su, Z., Liu, Z., Yu, X., A glass/PDMS electrophoresis microchip embedded with molecular imprinting SPE monolith for contactless conductivity detection. Microchem. J. 2014, 114, 223-228.

[82] Su, Z., Zhai, H., Chen, Z., Zhou, Q., Li, J., Liu, Z., Molecularly imprinted solid-phase extraction monolithic capillary column for selective extraction and sensitive determination of safranine $T$ in wolfberry. Anal. Bioanal. Chem. 2014, 406, 1551-1556.

[83] Yan, W., Gao, R., Zhang, Z., Wang, Q., Jiang, C. V., Yan, C., Capillary electrochromatographic separation of ionizable compounds with a molecular imprinted monolithic cationic exchange column. J. Sep. Sci. 2003, 26, 555-561.

[84] Cacho, C., Schweitz, L., Turiel, E., Pérez-Conde, C., Molecularly imprinted capillary electrochromatography for selective determination of thiabendazole in citrus samples. $J$. Chromatogr. A 2008, 1179, 216-223.

[85] Li, J., Zhai, H., Chen, Z., Zhou, Q., Liu, Z., Su, Z., Preparation and evaluation of a novel molecularly imprinted SPE monolithic capillary column for the determination of auramine $O$ in shrimp: Sample Preparation. J. Sep. Sci. 2013, 36, 3608-3614.

[86] Bouvarel, T., Delaunay, N., Pichon, V., Selective extraction of cocaine from biological samples with a miniaturized monolithic molecularly imprinted polymer and on-line analysis in nanoliquid chromatography. Anal. Chim. Acta 2020, 1096, 89-99.

[87] Tan, J., Jiang, Z.-T., Li, R., Yan, X.-P., Molecularly-imprinted monoliths for sample treatment and separation. TrAC Trends Anal. Chem. 2012, 39, 207-217.

[88] Liao, S., Wang, X., Lin, X., Xie, Z., Preparation and characterization of a molecularly imprinted monolithic column for pressure-assisted CEC separation of nitroimidazole drugs. Electrophoresis 2010, 31, 2822-2830.

[89] Ou, J., Dong, J., Tian, T., Hu, J., Ye, M., Zou, H., Enantioseparation of tetrahydropalmatine and Tröger's base by molecularly imprinted monolith in capillary electrochromatography. J. Biochem. Biophys. Methods 2007, 70, 71-76.

[90] Schweitz, L., Andersson, L. I., Nilsson, S., Capillary electrochromatography with molecular imprint-based selectivity for enantiomer separation of local anaesthetics. J. Chromatogr. A 1997, 792, 401-409.

[91] Zheng, C., Liu, Z., Gao, R., Zhang, L., Zhang, Y., Recognition of oxytocin by capillary electrochromatography with monolithic tetrapeptide-imprinted polymer used as the stationary phase. Anal. Bioanal. Chem. 2007, 388, 1137-1145.

[92] Zheng, C., Liu, Z.-S., Gao, R.-Y., Zhang, Y.-K., Mechanism of molecular recognition on tetrapetideimprinted monolith by capillary electrochromatography. Chin. J. Chem. 2008, 26, 1857-1862.

[93] Zhang, Q., Xiao, X., Li, G., Porous molecularly imprinted monolithic capillary column for on-line extraction coupled to high-performance liquid chromatography for trace analysis of antimicrobials in food samples. Talanta 2014, 123, 63-70.

[94] Lin, Z., Lin, Y., Sun, X., Yang, H., Zhang, L., Chen, G., One-pot preparation of a molecularly imprinted hybrid monolithic capillary column for selective recognition and capture of lysozyme. J. Chromatogr. A 2013, 1284, 8-16. 
[95] Bi, X., Tian, W., Wang, X., Cao, W., Gao, L., Fan, S., Wang, Y., Wang, M., Niu, L., Preparation of a POSS-hybridized molecularly imprinted monolith for the analysis of baicalin and its analogues in a microwave-assisted extract from Scutellaria baicalensis by means of on-line SPME-HPLC and off-line LC-MS/MS. Anal. Methods 2019, 11, 2351-2361.

[96] Aşır, S., Derazshamshir, A., Yılmaz, F., Denizli, A., Triazine herbicide imprinted monolithic column for capillary electrochromatography: CE and CEC. Electrophoresis 2015, 36, 2888-2895.

[97] Aşir, S., Sari, D., Derazshamshir, A., Yilmaz, F., Şarkaya, K., Denizli, A., Dopamine-imprinted monolithic column for capillary electrochromatography. Electrophoresis 2017, 38, 3003-3012.

[98] Şarkaya, K., Aşir, S., Göktürk, I., Yilmaz, F., Yavuz, H., Denizli, A., Electrochromatographic separation of hydrophobic amino acid enantiomers by molecularly imprinted capillary columns. Process Biochem. 2020, 92, 69-77.

[99] Lin, Z., Wang, J., Tan, X., Sun, L., Yu, R., Yang, H., Chen, G., Preparation of boronatefunctionalized molecularly imprinted monolithic column with polydopamine coating for glycoprotein recognition and enrichment. J. Chromatogr. A 2013, 1319, 141-147.

[100] He, J.-X., Fang, G., Yao, Y., Wang, S., Preparation and characterization of molecularly imprinted silica monolith for screening sulfamethazine. J. Sep. Sci. 2010, 33, 3263-3271.

[101] Zhang, C., Cai, J., Duan, Y., Xu, L., Fang, G., Wang, S., Synthesis, characterization and application of organic-inorganic hybrid and carbaryl-imprinted capillary monolithic column. Chem. Res. Chin. Univ. 2014, 30, 374-378.

[102] Wang, H.-F., Zhu, Y.-Z., Yan, X.-P., Gao, R.-Y., Zheng, J.-Y., A room temperature ionic liquid (RTIL)mediated, non-hydrolytic sol-gel methodology to prepare molecularly imprinted, silica-based hybrid monoliths for chiral separation. Adv. Mater. 2006, 18, 3266-3270.

[103] Huang, L., Zhai, H., Liang, G., Su, Z., Yuan, K., Lu, G., Pan, Y., Chip-based dual-molecularly imprinted monolithic capillary array columns coated $\mathrm{Ag} / \mathrm{GO}$ for selective extraction and simultaneous determination of bisphenol $A$ and nonyl phenol in fish samples. J. Chromatogr. $A$ 2016, 1474, 14-22.

[104] Zhao, T., Wang, Q., Li, J., Qiao, X., Xu, Z., Study on an electrochromatography method based on organic-inorganic hybrid molecularly imprinted monolith for determination of trace trichlorfon in vegetables: Determination of trichlorfon in vegetables. J. Sci. Food Agric. 2014, 94, 19741980.

[105] Zhai, H., Liang, G., Guo, X., Chen, Z., Yu, J., Lin, H., Zhou, Q., Novel coordination imprinted polymer monolithic column applied to the solid-phase extraction of flumequine from fish samples. J. Chromatogr. B 2019, 1118-1119, 55-62.

[106] Zhai, H., Huang, L., Chen, Z., Su, Z., Yuan, K., Liang, G., Pan, Y., Chip-based molecularly imprinted monolithic capillary array columns coated $\mathrm{GO} / \mathrm{SiO} 2$ for selective extraction and sensitive determination of rhodamine B in chili powder. Food Chem. 2017, 214, 664-669.

[107] Liang, G., Guo, X., Tan, X., Mai, S., Chen, Z., Zhai, H., Molecularly imprinted monolithic column based on functionalized $\beta$-cyclodextrin and multi-walled carbon nanotubes for selective recognition of benzimidazole residues in citrus samples. Microchem. J. 2019, 146, 1285-1294.

[108] Ou, J., Li, X., Feng, S., Dong, J., Dong, X., Kong, L., Ye, M., Zou, H., Preparation and evaluation of a molecularly imprinted polymer derivatized silica monolithic column for capillary electrochromatography and capillary liquid chromatography. Anal. Chem. 2007, 79, 639-646.

[109] Courtois, J., Fischer, G., Sellergren, B., Irgum, K., Molecularly imprinted polymers grafted to flow through poly(trimethylolpropane trimethacrylate) monoliths for capillary-based solid-phase extraction. J. Chromatogr. A 2006, 1109, 92-99.

[110] Oxelbark, J., Legido-Quigley, C., Aureliano, C. S. A., Titirici, M.-M., Schillinger, E., Sellergren, B., Courtois, J., Irgum, K., Dambies, L., Cormack, P. A. G., Sherrington, D. C., De Lorenzi, E., Chromatographic comparison of bupivacaine imprinted polymers prepared in crushed monolith, microsphere, silica-based composite and capillary monolith formats. J. Chromatogr. A 2007, 1160, 215-226. 
[111] Wei, Z. H., Mu, L. N., Pang, Q. Q., Huang, Y. P., Liu, Z. S., Preparation and characterization of grafted imprinted monolith for capillary electrochromatography: CE and CEC. Electrophoresis 2012, 33, 3021-3027.

[112] Huang, B.-Y., Chen, Y.-C., Wang, G.-R., Liu, C.-Y., Preparation and evaluation of a monolithic molecularly imprinted polymer for the chiral separation of neurotransmitters and their analogues by capillary electrochromatography. J. Chromatogr. A 2011, 1218, 849-855.

[113] Wen, L., Tan, X., Sun, Q., Svec, F., Lv, Y., "Smart" molecularly imprinted monoliths for the selective capture and easy release of proteins: Other Techniques. J. Sep. Sci. 2016, 39, 32673273.

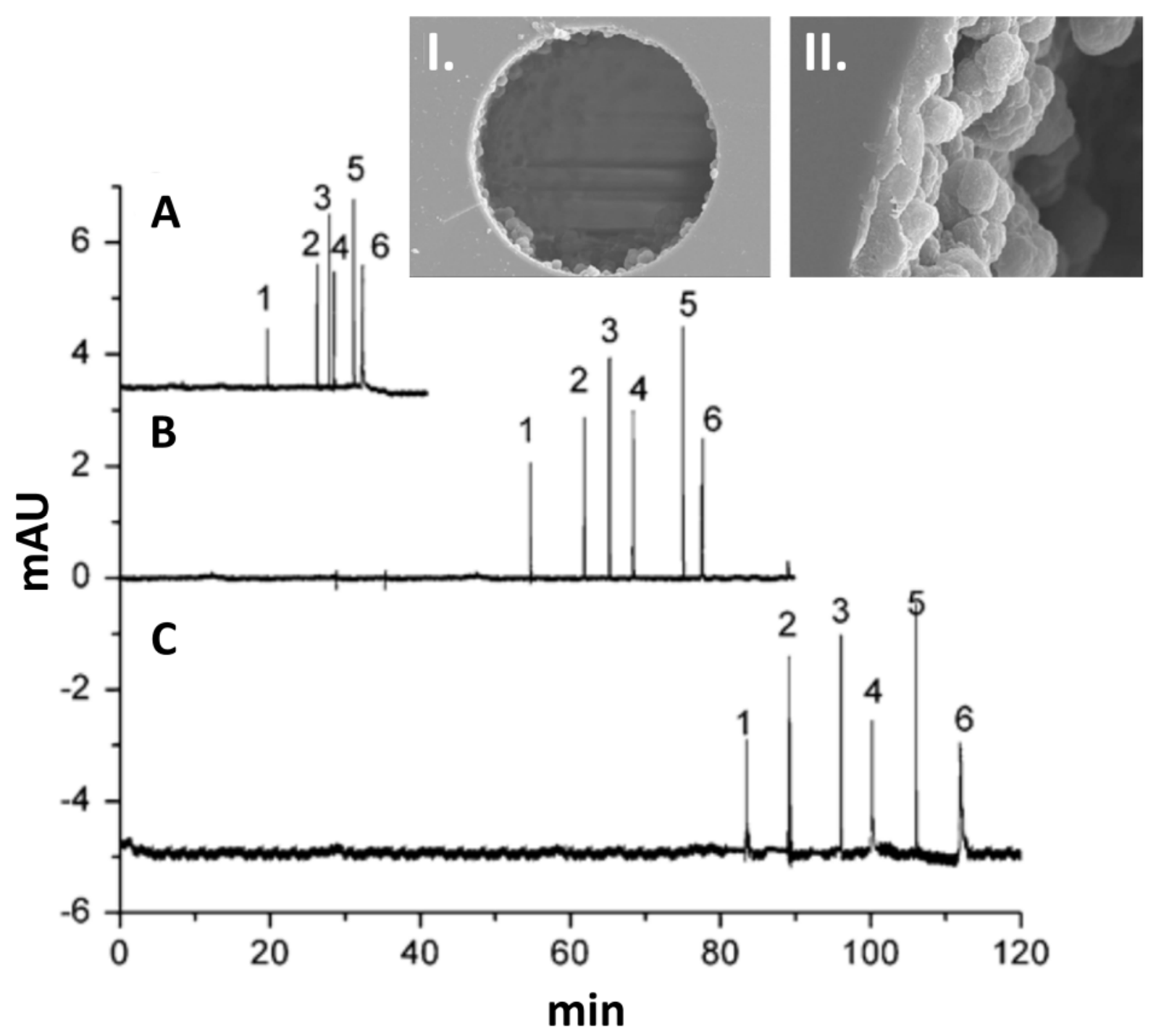

Figure 1. Open tubular CEC separation with a MIP stationary phase in a capillary (50 $\mu \mathrm{m}$ i.d.) with a length of $1 \mathrm{~m} \mathrm{(A),} 2 \mathrm{~m}$ (B), and $3 \mathrm{~m}(\mathrm{C})$. CEC conditions: ACN/sodium acetate $60 \mathrm{mM}$ at pH $3.5(92 / 8$ $(\mathrm{v} / \mathrm{v})$ ), applied voltage of $+30 \mathrm{kV}$, UV detection at $214 \mathrm{~nm}$. Peaks attribution: Acetone (1), Racemic naproxen (2), Racemic ibuprofen (3), Racemic fenoprofen (4), R-ketoprofen (5), and S-ketoprofen (6). Scanning electron micrograph of the MIP synthesized with S-ketoprofen in the capillary cross section (I) and enlargement in the region of the capillary wall (II). Adapted from [44]. 

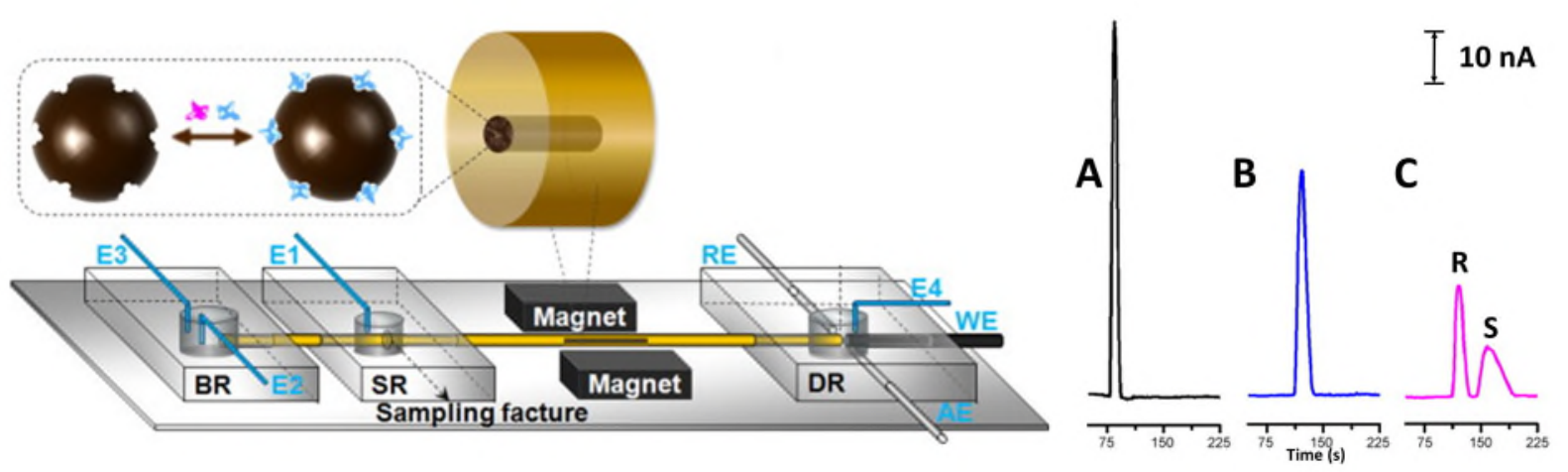

Figure 2. (Left) MIP magnetic nanoparticles used in a chip device and (Right) chromatograms of the CEC separation of R,S-ofloxacin in a microchannel empty (A) or filled with a NIP (B) or a MIP (C). CEC conditions: ACN/acetate buffer $40 \mathrm{mM}$ at pH $4.0(9 / 1(\mathrm{v} / \mathrm{V}))$, detection potential of $+1.0 \mathrm{~V}$, injection voltage of $200 \mathrm{~V}$ for $2 \mathrm{~s}$ and separation voltage of $1200 \mathrm{~V}$. AE: Auxiliary electrode; BR: Buffer reservoir; DR: Detection reservoir; E1, E2, E3, and E4: Electrodes for applying sampling and separation voltages; RE: Reference electrode; SR: Sample reservoir; WE: Working electrode. Adapted from [66].

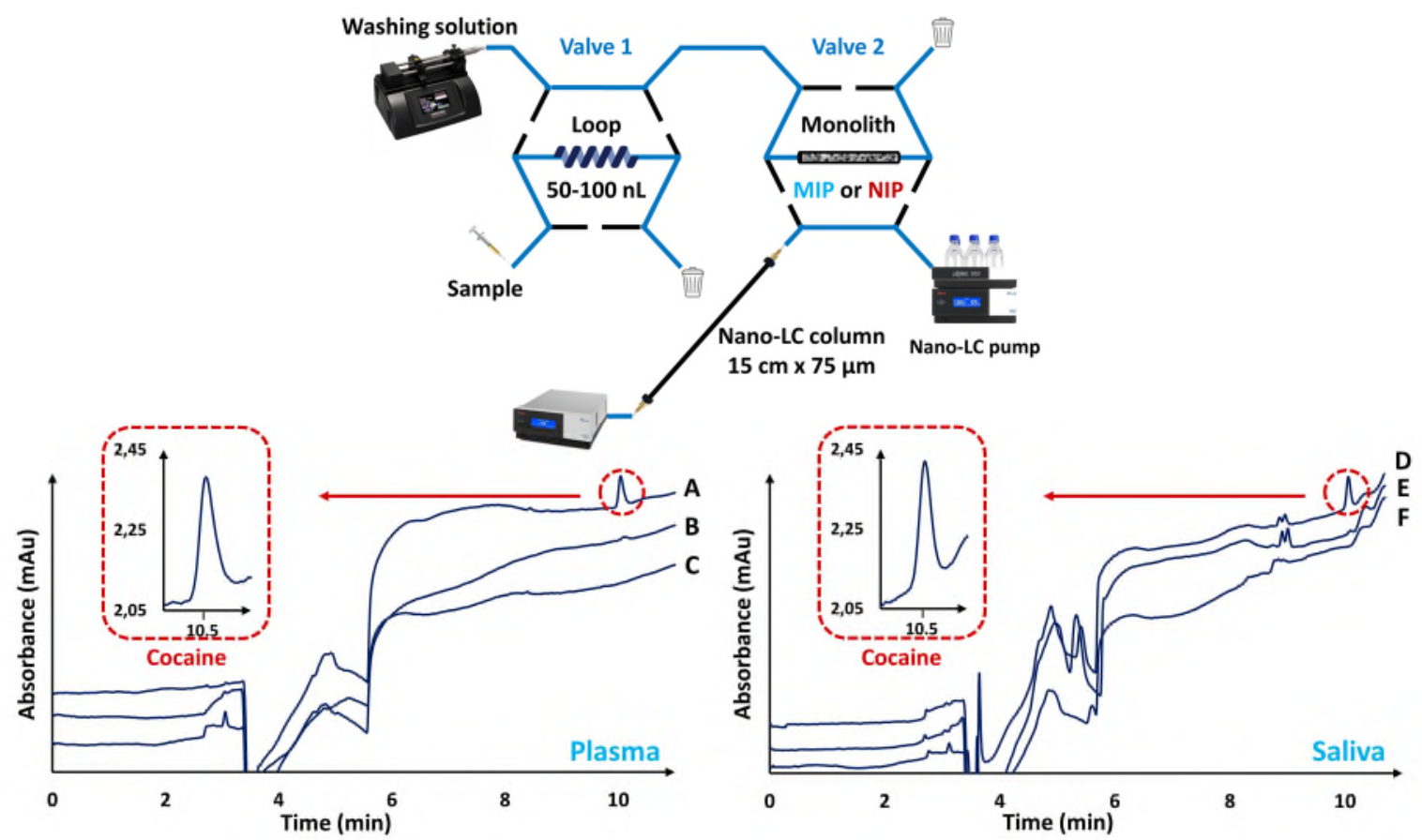

Figure 3. Set-up of the on-line coupling of the monolithic MIP/NIP (50 $\mathrm{mm} \times 100 \mu \mathrm{m}$ i.d.) with nanoLCUV (Top). Chromatograms (Left) obtained after the extraction on MIP (A) and NIP (B) of $50 \mathrm{~nL}$ of plasma spiked with cocaine (equivalent to $100 \mathrm{ng} \mathrm{mL}^{-1}$ in plasma) compared to the blank plasma (C) on MIP and chromatograms (Right) obtained after the extraction on MIP (D) and NIP (E) of $50 \mathrm{~nL}$ of saliva spiked with $50 \mathrm{ng} \mathrm{mL}^{-1}$ of cocaine compared to the blank plasma (F) on MIP. Adapted from [86]. 
Table 1. Conditions of synthesis and performances of MIPs in open tubular format.

\begin{tabular}{|c|c|c|c|c|c|c|c|c|}
\hline Target* & $\mathrm{M} / \mathrm{CL} /$ Solvent (v:v) & $\begin{array}{l}\mathrm{T} / \mathrm{M} / \mathrm{CL} \\
(\mathrm{mol} / \mathrm{mol} / \mathrm{mol})\end{array}$ & $\begin{array}{l}\text { Dimensions } \\
(\mathrm{L}(\mathrm{I}) \times \text { i.d. } \mathrm{xt}) * *\end{array}$ & $\alpha$ & $\begin{array}{l}\text { Rs }(R S D, \\
\text { repetitio } \\
n \\
\text { number) }\end{array}$ & $\begin{array}{l}\mathrm{N} \text { in plates } / \mathrm{m} \\
\text { (RSD, repetition } \\
\text { number) }\end{array}$ & $\begin{array}{l}\text { Other parameter RSD } \\
\text { (repetition number) }\end{array}$ & Ref. \\
\hline \multicolumn{9}{|l|}{ CEC applications } \\
\hline $\begin{array}{l}\text { Adenosine, Thymine, } \\
\text { Guanine, Cytosine (9- } \\
\text { Ethyladenine) }\end{array}$ & MAA/EGDMA/ACN & $1 / 12 / 18$ & $70 \mathrm{~cm}(50) \times 75 \mu \mathrm{m} \times-$ & - & - & $2,600-75,300$ & $\mathrm{t}_{\mathrm{r}}:<6,69 \%(\mathrm{n}=7)$ & [45] \\
\hline $\mathrm{R}, \underline{\mathrm{S} \text {-Amlodipine }}$ & $\begin{array}{l}\text { MAA+MA0702/MAM/Toluene:Iso } \\
\text { octane }(90: 10)\end{array}$ & $1 / 4+4.7 / 4$ & $\begin{array}{l}47.5 \mathrm{~cm}(37) \times 100 \mu \mathrm{m} \times 0.1- \\
0.2 \mu \mathrm{m}\end{array}$ & - & $\begin{array}{l}14.8(< \\
3.01 \% \\
\mathrm{n}_{\mathrm{B} / \mathrm{B}}=\text { ?) }\end{array}$ & $\begin{array}{l}35,300(\mathrm{R}) \\
31,700(\mathrm{~S})\end{array}$ & - & [46] \\
\hline $\mathrm{R}, \underline{\mathrm{S} \text {-Amlodipine }}$ & MAA/Ov-POSS/Chloroform & $1 / 3 / 1.5$ & $\begin{array}{l}47.5 \mathrm{~cm}(37) \times 100 \mu \mathrm{m} \times 0.1- \\
0.2 \mu \mathrm{m}\end{array}$ & 2.60 & $\begin{array}{l}33.0 \\
(2.08 \% \\
\mathrm{n}_{\mathrm{B} / \mathrm{B}}=\text { ?) }\end{array}$ & $\begin{array}{l}77,600(\mathrm{R}) \\
54,000(\mathrm{~S}) \\
\left(2.57-4.06 \%, \mathrm{n}_{\mathrm{B} / \mathrm{B}}\right. \\
=?)\end{array}$ & $\mathrm{t}_{\mathrm{r}}: 0.80-1.29 \%\left(\mathrm{n}_{\mathrm{B} / \mathrm{B}}=\right.$ ?) & [47] \\
\hline Boc-D, L-Trp & AA/EGDMA/ACN:Isooctane (96:4) & $1 / 4 / 20$ & $8 \mathrm{~cm} \mathrm{(-)} \times 25 \mu \mathrm{m} \times 2.5 \mu \mathrm{m}$ & - & 1.3 & - & $\mathrm{t}_{\mathrm{r}}: 3.3-3.6 \%\left(\mathrm{n}_{\mathrm{c} / \mathrm{c}}=3\right)$ & [39] \\
\hline $\begin{array}{l}\text { Dansyl-D,L- } \\
\text { phenylalanine }\end{array}$ & $\begin{array}{l}\text { MAA+VP/EGDMA/Toluene:ACN } \\
(87.5: 12.5)\end{array}$ & $1 / 7.4+7.4 / 36.3$ & $100 \mathrm{~cm}(85) \times 25 \mu \mathrm{m} \times-$ & - & - & $\begin{array}{l}248,600(D) \\
8,00(L)\end{array}$ & EOF: $2.2 \%(n=6)$ & [38] \\
\hline $\mathrm{R}$, S-Ketoprofen & $\begin{array}{l}\text { MAA+4-SSA/EGDMA/ACN:2- } \\
\text { Propanol (90:10) }\end{array}$ & $1 / 4.8+0.5 / 15.4$ & $100 \mathrm{~cm}(91.4) \times 25 \mu \mathrm{m} \times 1-4 \mu \mathrm{m}$ & - & 4.0 & $\begin{array}{l}1,130,000(\mathrm{R}) \\
460,000(\mathrm{~S}) \\
\left(<2.2 \%, \mathrm{n}_{\mathrm{B} / \mathrm{B}}=3\right)\end{array}$ & - & [40] \\
\hline $\mathrm{R}, \underline{\mathrm{S}-\text { Ketoprofen }}$ & $\begin{array}{l}\text { MAA+4-SSA/EGDMA/ACN:2- } \\
\text { Propanol (90:10) }\end{array}$ & $1 / 4.8+0.5 / 15.4$ & $36.4 \mathrm{~cm}(28) \times 50 \mu \mathrm{m} \times 1-4 \mu \mathrm{m}$ & - & 10.5 & $\begin{array}{l}156,000(\mathrm{R}) \\
10,000(\mathrm{~S}) \\
\left(<3.5 \%, \mathrm{n}_{\mathrm{B} / \mathrm{B}}=3\right)\end{array}$ & - & [42] \\
\hline $\begin{array}{l}\text { Phospholipids (S- } \\
\text { Ketoprofen) }\end{array}$ & $\begin{array}{l}\text { MAA+4-SSA/EGDMA/ACN:2- } \\
\text { Propanol (90:10) }\end{array}$ & $1 / 4.8+0.5 / 15.4$ & $30 \mathrm{~cm}(-) \times 50 \mu \mathrm{m} \times-$ & - & - & - & tr: $2.80-4.44 \%(n=?)$ & [43] \\
\hline R,S-Propanolol & MAA/TRIM/DCM & $1 / 8 / 8$ & $\begin{array}{l}35 \mathrm{~cm}(26.5) \times 25-50 \mu \mathrm{m} \times 0.15- \\
2 \mu \mathrm{m}\end{array}$ & - & - & - & - & [51] \\
\hline $\begin{array}{l}\text { D,L-Tyrosine, D,L- } \\
\text { Tryptophan }\end{array}$ & AA/EGDMA/ACN:Isooctane (96:4) & $1+3 / 16 / 80$ & $6 \mathrm{~cm}(-) \times 25 \mu \mathrm{m} \times 2 \mu \mathrm{m}$ & - & $\begin{array}{l}1.0 \\
1.0\end{array}$ & - & $\mathrm{t}_{\mathrm{r}}: 3.8-5.2 \%\left(\mathrm{n}_{\mathrm{c} / \mathrm{c}}=6\right)$ & [41] \\
\hline D,L-Zopiclone & $\begin{array}{l}\text { MAA/EGDMA/Toluene:Isooctane: } \\
\text { DMSO (50:20:30) }\end{array}$ & 1/4.6/17.4 & $50 \mathrm{~cm}(36) \times 100 \mu \mathrm{m} \times 1-10 \mu \mathrm{m}$ & - & 5.4 & $\begin{array}{l}37,900(\mathrm{~L}) \\
21,400(\mathrm{D}) \\
\left(8.1 \%, \mathrm{n}_{\mathrm{C} / \mathrm{C}}=3\right)\end{array}$ & EOF: $4.4 \%(n=5)$ & [48] \\
\hline
\end{tabular}




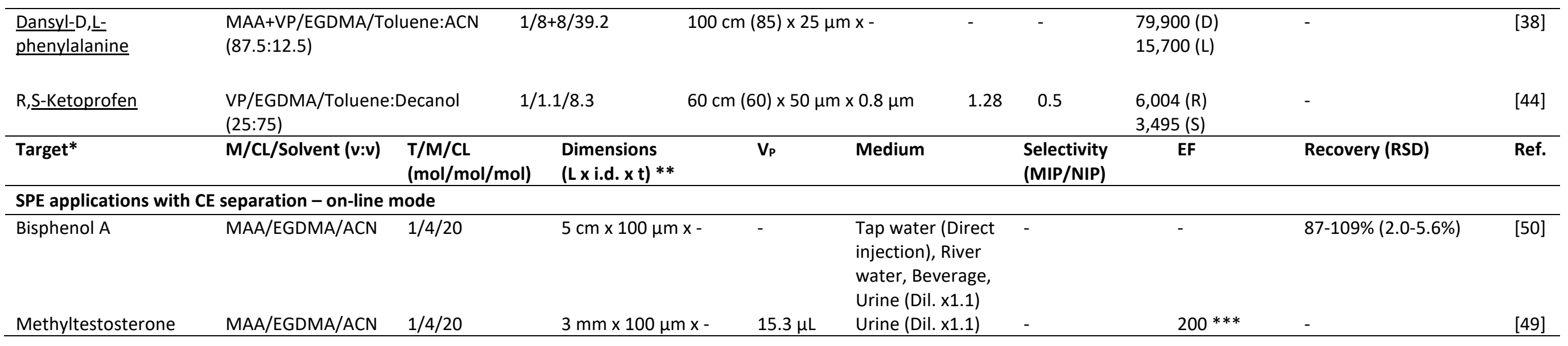

* Template indicated in bracket when different from target or underlined for a mixture of targets.

** $L$ (I) $x$ i.d. $x$ t: total length (effective length in $\mathrm{cm}$ ) $x$ internal diameter $x$ MIP thickness.

$* * *$ Results obtained in pure medium.

4-SSA: 4-styrenesulfonic acid; Boc-Trp: N-(tert-Butoxycarbonyl)-tryptophan; MA0702: Methacryllsobutyl polyhedral oligomeric silsesquioxanes; MAM: 2-Methacrylamidopropyl methacrylate; $\mathrm{n}_{\mathrm{B} / \mathrm{B}}$ : Batch-to-batch repetition number; $\mathrm{n}_{\mathrm{C} / \mathrm{C}}$ : Column-to-column repetition number; Ov-POSS: Octavinyl-modified polyhedral oligomeric silsesquioxanes; $t_{r}$ : Retention time; $V_{p}$ : Percolation volume. 
Table 2. Conditions of synthesis and performances of MIPs particles packed into a miniaturized device.

\begin{tabular}{|c|c|c|c|c|c|c|c|c|}
\hline Target & $\begin{array}{l}\text { MIP material } \\
\text { (Diameter) }\end{array}$ & $\begin{array}{l}\text { Immobilization } \\
\text { method }\end{array}$ & Dimensions & $\mathbf{V}_{\mathbf{P}}$ & Medium & Selectivity (MIP/NIP) & $\begin{array}{l}\text { Recovery (RSD, number } \\
\text { of repetitions) }\end{array}$ & Ref. \\
\hline \multicolumn{9}{|l|}{ SPE applications } \\
\hline $\begin{array}{l}\text { Atrazine, DEA, } \\
\text { DIA, DEIA }\end{array}$ & $\begin{array}{l}\text { SupelMIP Triazine } \\
(55 \mu \mathrm{m})\end{array}$ & $\begin{array}{l}\text { Capillary restriction } \\
\text { (75 } \mu \mathrm{m} \text { i.d.) }\end{array}$ & $\begin{array}{l}\text { Fused silica capillary } \\
(2 \mathrm{~mm} \times 150 \mu \mathrm{m} \text { i.d.) }\end{array}$ & $2.7 \mu \mathrm{L}$ & $\begin{array}{l}\text { Urine (Dil. } \\
\text { x1.008) }\end{array}$ & - & $92-102 \%(9-11 \%, n=3)$ & [53] \\
\hline $\begin{array}{l}\text { Danofloxacin, } \\
\text { Sarafloxacin, } \\
\text { Difloxacin, } \\
\text { Enrofloxacin, } \\
\text { Ciprofloxacin, } \\
\text { Flumequine, } \\
\text { Marbofloxacin, } \\
\text { Oxolinic acid }\end{array}$ & $\begin{array}{l}\text { SupelMIP Quinolones } \\
(57 \mu \mathrm{m})\end{array}$ & $\begin{array}{l}\text { Capillary restriction } \\
\text { (50 } \mu \mathrm{m} \text { i.d.) }\end{array}$ & $\begin{array}{l}\text { Fused silica capillary } \\
(2 \mathrm{~mm} \text { x } 150 \mu \mathrm{m} \text { i.d.) }\end{array}$ & $22 \mu \mathrm{L}$ & $\begin{array}{l}\text { Milk (PP \& } \\
\text { Dil.) }\end{array}$ & - & $70-102 \%(3-12 \%, n=6)$ & [54] \\
\hline Z-L-Phe-OH-NBD & $\begin{array}{l}\text { Poly(MAA-VP-co- } \\
\text { EGDMA) } \\
(<110 \mu \mathrm{m})\end{array}$ & $\begin{array}{l}\text { Channel restriction } \\
\text { (105 } \mu \mathrm{m} \text { i.d.) }\end{array}$ & $\begin{array}{l}\text { Chip channel } \\
(220 \mu \mathrm{m} \text { i.d.) }\end{array}$ & $20 \mu \mathrm{L}$ & Pure medium & Adsorption: $61 / 18 \%$ & - & [56] \\
\hline Terbutaline & $\begin{array}{l}\text { Poly(MAA-co- } \\
\text { EGDMA) } \\
(<50 \mu \mathrm{m})\end{array}$ & $\begin{array}{l}\text { Channel restriction } \\
(200 \mu \mathrm{m} \times 150 \mu \mathrm{m})\end{array}$ & $\begin{array}{l}\text { Chip micro-cell } \\
(10 \mathrm{~cm} \times 1 \mathrm{~mm} \times 500 \mu \mathrm{m})\end{array}$ & $12 \mu \mathrm{L}$ & $\begin{array}{l}\text { Human serum } \\
\text { (Filtration) }\end{array}$ & - & $98-108 \%$ & [55] \\
\hline
\end{tabular}

DEA: Desethylatrazine; DIA : Desisopropylatrazine; DEIA: Desethyldesisopropylatrazine ; PP: protein precipitation; $V_{P}$ : Percolation volume; Z-LPhe-OH-NBD: Z-L-phenylalanine-nitrobenzoxadiazole. 
Table 3. Conditions of synthesis and performances of MIPs by imprinting the surface of core particles and introducing them in miniaturized devices.

\begin{tabular}{|c|c|c|c|c|c|c|c|}
\hline Target* & MIP material & $\begin{array}{l}\text { Nanoparticles core (Diameter) or } \\
\text { immobilization method }\end{array}$ & Dimensions & Rs & $\begin{array}{l}\mathbf{N} \\
\text { (plates } / \mathrm{m})\end{array}$ & $\begin{array}{l}\text { Retention time RSD } \\
\text { (repetition number) }\end{array}$ & Ref. \\
\hline \multicolumn{8}{|l|}{ CEC applications } \\
\hline $\mathrm{D}, \underline{\mathrm{L}-\text { Histidine }}$ & $\begin{array}{l}\text { Poly(Norepinephrine) } \\
\text { (Thickness }=7-8 \mathrm{~nm} \text { ) }\end{array}$ & $\mathrm{Fe}_{3} \mathrm{O}_{4}$ particles $(\simeq 385 \mathrm{~nm})$ & $\begin{array}{l}\text { PDMS channel } \\
(2 \mathrm{~cm} \times 50 \mu \mathrm{m} \times 18 \mu \mathrm{m})\end{array}$ & 1.63 & - & - & {$[61]$} \\
\hline$\underline{\mathrm{R}}, \mathrm{S}$-Mandelic acid & $\begin{array}{l}\text { Poly(Norepinephrine) } \\
\text { (Thickness }=7-8 \mathrm{~nm} \text { ) }\end{array}$ & $\mathrm{Fe}_{3} \mathrm{O}_{4}$ particles $(\simeq 385 \mathrm{~nm})$ & $\begin{array}{l}\text { PDMS channel } \\
(2 \mathrm{~cm} \times 50 \mu \mathrm{m} \times 18 \mu \mathrm{m})\end{array}$ & 1.82 & $\begin{array}{l}3,200(S) \\
5,400(R)\end{array}$ & $3.3-4.6 \%\left(n_{c / c}=3\right)$ & [61] \\
\hline D,L-Tryptophan & $\begin{array}{l}\text { Poly(Norepinephrine) } \\
\text { (Thickness }=6 \mathrm{~nm} \text { ) }\end{array}$ & $\mathrm{Fe}_{3} \mathrm{O}_{4}$ particles $(\simeq 100 \mathrm{~nm})$ & $\begin{array}{l}\text { PDMS channel } \\
(1 \mathrm{~cm} \times 50 \mu \mathrm{m} \times 18 \mu \mathrm{m})\end{array}$ & 1.84 & $\begin{array}{l}128,000(D) \\
183,000(L)\end{array}$ & $4.2-4.7 \%\left(n_{B / B}=3\right)$ & {$[60]$} \\
\hline D,L-Tryptophan & $\begin{array}{l}\text { Poly(Dopamine) } \\
\text { (Thickness }=8 \mathrm{~nm})\end{array}$ & $\mathrm{Fe}_{3} \mathrm{O}_{4}$ particles $(\simeq 130 \mathrm{~nm})$ & $\begin{array}{l}\text { PDMS channel } \\
(2 \mathrm{~cm} \times 50 \mu \mathrm{m} \times 18 \mu \mathrm{m})\end{array}$ & 1.65 & $\begin{array}{l}78,500(\mathrm{D}) \\
175,000(\mathrm{~L})\end{array}$ & $3.9-4.2 \%\left(n_{B / B}=3\right)$ & [59] \\
\hline R,S-Ofloxacin & $\begin{array}{l}\text { Poly(MAA-co-EGDMA) } \\
\text { (Thickness }=87-88 \mathrm{~nm} \text { ) }\end{array}$ & $\begin{array}{l}\text { Commercial hydroxyl group modified } \\
\text { superparamagnetic nanospheres }(\simeq 25 \mathrm{~nm})\end{array}$ & $\begin{array}{l}\text { Fused silica capillary } \\
(5 \mathrm{~mm} \times 25 \mu \mathrm{m} \text { i.d.) }\end{array}$ & 1.46 & - & $4.3-5.6 \%\left(n_{c / c}=3\right)$ & [62] \\
\hline
\end{tabular}

* Template underlined for a mixture of targets.

$\mathrm{n}_{\mathrm{B} / \mathrm{B}}$ : Batch-to-batch; $\mathrm{n}_{\mathrm{C} / \mathrm{C}}$ : Column-to-column; $\mathrm{t}_{\mathrm{r}}$ : Retention time. 
Table 4. Conditions of in situ synthesis of monolithic MIPs in capillaries.

\begin{tabular}{|c|c|c|c|c|c|}
\hline Target * & Activator & Monomer/CL/Solvent (v:v) & $\mathrm{T} / \mathrm{M} / \mathrm{CL}(\mathrm{mol} / \mathrm{mol} / \mathrm{mol})$ & Initiation & Ref. \\
\hline 2,4-Aminopyridine & p-MAPS & MAA/EGDMA/ACN & $1 / 4 / 20$ & AIBN $/ 60^{\circ} \mathrm{C}, 12 \mathrm{~h}$ & [79] \\
\hline Dopamine, Norepinephrine & Y-MAPS & MAPA/EGDMA/EtOH:MeOH (60:40) & $1 / ? / 33.5$ & AIBN $/ 70^{\circ} \mathrm{C}, 40 \mathrm{~min}$ & [93] \\
\hline Histamine, Serotonin +3 analogs & Y-MAPS & IA/EGDMA/DMF & $1+1 / 5 / 18$ & AIBN $/ 55^{\circ} \mathrm{C}, 6 \mathrm{~h}$ & [74] \\
\hline $\begin{array}{l}(-) \text {-Norepinephrine, }(+)- \\
\text { Norepinephrine }+5 \text { analogs }\end{array}$ & Y-MAPS & IA/EGDMA/DMF & $1 / 9.2 / 19$ & AIBN $/ 65^{\circ} \mathrm{C}, 17 \mathrm{~min}$ & [108] \\
\hline 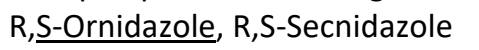 & Y-MAPS & MAA+VP/EGDMA/Toluene:Dodecanol (10:90, w:w) & $1 / 0.75+0.75 / 6$ & AIBN $/ 56^{\circ} \mathrm{C}, 20 \mathrm{~h}$ & {$[71]$} \\
\hline $\mathrm{R}, \mathrm{S}$-Ornidazole +5 analogs & Y-MAPS & HEMA+DMAEMA/EGDMA/Toluene:Dodecanol (12:88, w:w) & $1 / 0.75+0.75 / 6$ & AIBN $/ 56^{\circ} \mathrm{C}, 24 \mathrm{~h}$ & [84] \\
\hline $\mathrm{D}, \mathrm{L}$-Phenylalanine & Y-MAPS & MAPA/EGDMA/EtOH:MeOH (60:40) & $1 / ? / 33$ & $\mathrm{AIBN} / 70^{\circ} \mathrm{C}, 40 \mathrm{~min}$ & [94] \\
\hline $\mathrm{R}, \underline{\mathrm{S} \text {-Ropivacaine }}$ & Y-MAPS & MAA/TRIM/Toluene:Isooctane (99:1) & $1 / 12 / 12$ & $\begin{array}{l}\text { AIBN / UV, } 350 \mathrm{~nm},-20^{\circ} \mathrm{C} \text {, } \\
16 \mathrm{~h}\end{array}$ & [86] \\
\hline $\mathrm{R}, \underline{\mathrm{S}-\mathrm{TB}}$ & Y-MAPS & MAA/EGDMA/Toluene:Dodecanol (16:84) & $1 / 3 / 20$ & AIBN $/ 55^{\circ} \mathrm{C}, 10 \mathrm{~h}$ & {$[85]$} \\
\hline Thiabendazole & Y-MAPS & MAA/EGDMA/Toluene:Isooctane (96:4) & $1 / 4 / 20$ & AIBN / UV, RT, $1.5 \mathrm{~h}$ & {$[80]$} \\
\hline $\mathrm{D}, \underline{\mathrm{L}-\mathrm{THP}}$ & Y-MAPS & MAA/EGDMA/Toluene:Dodecanol (12:88) & $1 / 2 / 13$ & $\mathrm{AIBN} / 55^{\circ} \mathrm{C}, 10 \mathrm{~h}$ & {$[85]$} \\
\hline Trietazine, Cyanazine & Y-MAPS & MAPA/EGDMA/EtOH:MeOH (60:40) & $1 / ? / 12.2$ & $\mathrm{AIBN} / 70^{\circ} \mathrm{C}, 90 \mathrm{~min}$ & {$[92]$} \\
\hline D,L-Tryptophan & Y-MAPS & MAPA/EGDMA/EtOH:MeOH (60:40) & $1 / ? / 40.8$ & AIBN $/ 70^{\circ} \mathrm{C}, 40 \mathrm{~min}$ & [94] \\
\hline$D$, L-Tyrosine & Y-MAPS & MAPA/EGDMA/EtOH:MeOH (60:40) & $1 / ? / 36.2$ & AIBN $/ 70^{\circ} \mathrm{C}, 40 \mathrm{~min}$ & [94] \\
\hline$D, \overline{\text { L-Tyrosine }}$ & Y-MAPS & AA/EGDMA/ACN:Isooctane (67:33) & $1 / 4 / 40$ & AIBN $/ 60^{\circ} \mathrm{C}, 4 \mathrm{~h}$ & [73] \\
\hline $\mathrm{D}, \overline{\mathrm{L}-\mathrm{T} \text { yrosine }}+4$ analogs & Y-MAPS & MAA+VP/EGDMA/Toluene:Dodecanol (20:80) & $1 / 1.5+1.5 / 8.1$ & AIBN $/ 50^{\circ} \mathrm{C}, 12 \mathrm{~h}$ & [75] \\
\hline YPLG, Oxytocin & Y-MAPS & MAA/EGDMA/ACN:Isooctane (96:4) & $1 / 15 / 60$ & AIBN $/ 48^{\circ} \mathrm{C}, 3 \mathrm{~h}$ & [87] \\
\hline$\overline{\mathrm{YPLG}}, \mathrm{YPGL}$ & Y-MAPS & MAA/EGDMA/ACN:Isooctane (96:4) & $1 / 15 / 60$ & AIBN $/ 48^{\circ} \mathrm{C}, 3 \mathrm{~h}$ & {$[88]$} \\
\hline Aflatoxin $B_{1}(D M C)$ & APTES & $\begin{array}{l}\text { MAA/EGDMA/Carbon quantum dots/MeOH:Toluene } \\
(80: 20)\end{array}$ & $1 / 10 / 40$ & AIBN $/ 55^{\circ} \mathrm{C}, 6 \mathrm{~h}$ & [34] \\
\hline Auramine $\mathrm{O}$ & - & MAA/EGDMA/MeOH:Toluene:Dodecanol (20:20:60) & $1 / 4 / 20$ & AIBN / UV, $365 \mathrm{~nm}, 10 \mathrm{~h}$ & {$[81]$} \\
\hline Bisphenol A, Nonyl phenol & - & MAA/EGDMA/(Ag/GO)/MeOH:Toluene (77:23) & $1+1 / 10 / 60$ & AIBN $/ 60^{\circ} \mathrm{C}, 6 \mathrm{~h}$ & [99] \\
\hline Cannabidiol, $\Delta 9-\mathrm{THC}$ & $\begin{array}{l}\text { Vinyltrimethoxy } \\
\text { silane }\end{array}$ & MAA/EGDMA/DCM & $1 / 3 / 9$ & AIBN $/ 60^{\circ} \mathrm{C}, 24 \mathrm{~h}$ & [70] \\
\hline Cocaine & Y-MAPS & MAA/TRIM/ACN:Isooctane $(90: 10)$ & $1 / 4 / 20$ & AIBN $/ 60^{\circ} \mathrm{C}, 24 \mathrm{~h}$ & {$[82]$} \\
\hline Flumequine (Flumequine- $-\mathrm{n}^{2+}$ ) & SGO & VP+IA/EGDMA/MeOH: $\mathrm{H}_{2} \mathrm{O}(85: 15)$ & $1 / 2+2 / 30$ & AIBN $/ 60^{\circ} \mathrm{C}, 24 \mathrm{~h}$ & [101] \\
\hline $\begin{array}{l}\text { Fluoroquinolones (Pefloxacin } \\
\text { methane sulphonate) }\end{array}$ & $Y$-MAPES & MAA/DEGDMA/MeOH: $\mathrm{H}_{2} \mathrm{O}(77: 23)$ & $1 / 9.4 / 24.2$ & AIBN $/ 65^{\circ} \mathrm{C}, 16 \mathrm{~h}$ & [69] \\
\hline 8-OHdG (Guanosine) & $\gamma$-MAPES & AA+VP/MBAA/Dodecanol:DMSO (50:50) & $1 / 12.8+5.8 / 6.6$ & AIBN $/ 60^{\circ} \mathrm{C}, 18 \mathrm{~h}$ & {$[31]$} \\
\hline 8-OHdG (Guanosine) & $\gamma$-MAPES & AA+VP/MBAA/Dodecanol:DMSO (50:50) & $1 / 13+9 / 7$ & AIBN $/ 60^{\circ} \mathrm{C}, 20 \mathrm{~h}$ & {$[32]$} \\
\hline Rhodamine B & - & MAA/EGDMA/SGO/MeOH:Toluene: & $1 / 4 / 30$ & $\mathrm{AIBN} / 60^{\circ} \mathrm{C}, 4 \mathrm{~h}$ & [102] \\
\hline
\end{tabular}




\begin{tabular}{|c|c|c|c|c|c|}
\hline & & Dodecanol (17:33:50) & & & \\
\hline Safranin T & - & $\begin{array}{l}\text { MAA/EGDMA/MeOH:Toluene: } \\
\text { Dodecanol (9:36:55) }\end{array}$ & $1 / 4 / 20$ & $\mathrm{AIBN} / 60^{\circ} \mathrm{C}, 4 \mathrm{~h}$ & [78] \\
\hline$\underline{\mathrm{SQX}}+4$ analogs & p-MAPS & $\begin{array}{l}\text { MAA/EGDMA/DMF:para-Xylene: } \\
\text { Isooctane (23:54:23) }\end{array}$ & $1 / 9.7 / 23.6$ & $\begin{array}{l}\text { AlBN } / 60^{\circ} \mathrm{C}, 70 \mathrm{~h} \text { then } 120^{\circ} \mathrm{C} \text {, } \\
2 \mathrm{~h}\end{array}$ & [89] \\
\hline Thiabendazole +2 analogs & - & $\begin{array}{l}\text { MAA+A- } \beta-C D / E G D M A / S M W N T / T o l u e n e: M e O H: D o d e c a n o l \\
(33: 17: 50)\end{array}$ & $1 / 1+3.5 / 20$ & AIBN $/ 60^{\circ} \mathrm{C}, 4 \mathrm{~h}$ & [103] \\
\hline Auramine $\mathrm{O}$ & - & MAA/EGDMA/MeOH:Toluene:Dodecanol (20:20:60) & $1 / 4 / 20$ & AIBN / UV, $365 \mathrm{~nm}, 10 \mathrm{~h}$ & [77] \\
\hline 8-OHdG (Guanosine) & $\gamma$-MAPES & AA+VP/MBAA/Dodecanol:DMSO (50:50) & $1 / 13+6 / 7$ & AIBN $/ 60^{\circ} \mathrm{C}, 18 \mathrm{~h}$ & [33] \\
\hline Rose bengal & - & $\begin{array}{l}\text { MAA/EGDMA/MeOH:Toluene: } \\
\text { Dodecanol (17:33:50) }\end{array}$ & $1 / 4 / 20$ & $\mathrm{AIBN} / 55^{\circ} \mathrm{C}, 4.5 \mathrm{~h}$ & [76] \\
\hline $\begin{array}{l}\text { Acephate, Phosphamidon (4- } \\
\text { DMPTABA) }\end{array}$ & - & MAA/Y-MAPS/MeOH:Toluene (60:40) & $1 / 3 / 8.4$ & AIBN $/ 50^{\circ} \mathrm{C}, 18 \mathrm{~h}$ & [35] \\
\hline Baicalin & Y-MAPS & $\begin{array}{l}\text { VP/EGDMA+POSS/DMSO:1,4-Butanediol:Dodecanol } \\
(12.5: 12.5: 75)\end{array}$ & $1 / 4.2 / 9$ & $\mathrm{AIBN} / 60^{\circ} \mathrm{C}, 3 \mathrm{~h}$ & {$[91]$} \\
\hline$\underline{\text { Carbaryl }+2 \text { analogs }}$ & - & MAA/Y-MAPS/ACN:DCM (20:80) & $1 / 6 / 8$ & AIBN $/ 50^{\circ} \mathrm{C}, 12 \mathrm{~h}$ & [97] \\
\hline $\begin{array}{l}R, S-\text { Naproxen } \\
(S, R),(R, S),(S, S),(R, R)- \\
\text { Ractopamine }\end{array}$ & - & $\begin{array}{l}\text { MAA/ }{ }^{-M A P S} / \mathrm{BMIM}^{+} \mathrm{PF}_{6}^{-}: \mathrm{ACN}: \text { Chloroform }(4.5: 11.2: 84.3) \\
\text { AA/ } \mathrm{Y}-\mathrm{MAPS} / \mathrm{MeOH}: \text { Toluene }(60: 40)\end{array}$ & $\begin{array}{l}1 / 4.2 / 17.2 \\
1 / 3.1 / 7.5\end{array}$ & $\begin{array}{l}\text { AIBN } / 54^{\circ} \mathrm{C}, 6 \mathrm{~h} \\
\text { AIBN } / 60^{\circ} \mathrm{C}, 24 \mathrm{~h}\end{array}$ & $\begin{array}{l}{[98]} \\
{[72]}\end{array}$ \\
\hline Trichlorfon & - & MAA/Y-MAPS/MeOH:Toluene (60:40) & $1 / 2 / 8.4$ & AIBN $/ 50^{\circ} \mathrm{C}, 12 \mathrm{~h}$ & [100] \\
\hline
\end{tabular}

* Template indicated in bracket when different from target or underlined for a mixture of targets.

4-DMPTABA: 4-(dimethoxyphosphorothioylamino)butanoic acid; 8-OHdG: 8-Hydroxy-2'-deoxyguanosine; A- $\beta$-CD: Acryloyl- $\beta$-cyclodextrin; $\mathrm{Ag} / \mathrm{GO}$ : Silver-modified graphene oxide; APTES: 3-Aminopropyltriethoxysilane; BMIM+PF6 ${ }^{-}$: 1-Butyl-3-methylimidazolium hexafluorophosphate; DEGDMA: Di(ethylene glycol) dimethacrylate; DMAEMA: 2-(Dimethylamino)ethyl methacrylate; DMC: 5,7-Dimethoxycoumarin; DMF: N,Ndimethylformamide; K: Permeability; MBAA: N,N'-Methylenebis(acrylamide); MAPA: N-Methacryloyl-L-phenylalanine; RT: Room temperature; SGO: Silanized graphene oxide; SMWNT: Silanized multi-walled carbon nanotube; SQX: Sulfaquinoxaline; TB: Tröger's base; THP: Tetrahydropalmatine; TMOS: Tetramethyl orthosilicate; YPGL: Tyrosine-Proline-Glycine-Leucine; YPLG: Tyrosine-Proline-Leucine-Glycine; $\Delta 9$ THC: $\Delta$ 9-tetrahydrocannabinol; -MAPES: 3-(Triethoxysilyl)propyl methacrylate. 
Table 5. Conditions of synthesis of MIPs by surface functionalization on miniaturized core monolith.

\begin{tabular}{|c|c|c|c|c|c|}
\hline Target* & Core monolith & $\mathrm{T} / \mathrm{M} / \mathrm{CL}(\mathrm{mol} / \mathrm{mol} / \mathrm{mol})$ & Monomer/CL/Solvent (v:v) & Initiation & Ref. \\
\hline $\begin{array}{l}\text { Aflatoxins } B_{1}, B_{2}, G_{1} \text { and } G_{2} \\
\text { (DMC) }\end{array}$ & Poly(TRIM) & $0.3 / 4 / 20$ & MAA/EGDMA/Toluene & $\begin{array}{l}\text { AIBN } / 60^{\circ} \mathrm{C}, 24 \mathrm{~h} \\
\text { AIBN / UV, } 365 \mathrm{~nm}, 1 \mathrm{~h}, \\
0^{\circ} \mathrm{C}\end{array}$ & [36] \\
\hline $\mathrm{R}, \underline{\mathrm{S}-\text { Amlodipine }}$ & Poly(TRIM) & $1 / 4 / 20$ & MAA/EGDMA/Toluene:Isooctane (80:20) & AIBN $/ 53^{\circ} \mathrm{C}, 3 \mathrm{~h}$ & [107] \\
\hline Bupivacaine & Poly(TRIM) & $1 / 12 / 60$ & MAA/EGDMA/Toluene & AIBN / UV, $365 \mathrm{~nm}, 1 \mathrm{~h}$ & [106] \\
\hline $\begin{array}{l}\text { Bupivacaine, Mepivacaine, } \\
\text { S-Ropivacaine }\end{array}$ & Poly(TRIM) & $1 / 12 / 60$ & MAA/EGDMA/Toluene & AIBN / UV, $365 \mathrm{~nm}, 1 \mathrm{~h}$ & [105] \\
\hline Sulfamethazine & Poly(TMOS) & $1 / 5.9 / 21.1$ & MAA/EGDMA/BMIM+PF-'ACN:Toluene (6.25:31.25:62.5) & AlBN $/ 60^{\circ} \mathrm{C}, 30 \mathrm{~min}$ & {$[96]$} \\
\hline $\mathrm{R}, \underline{\mathrm{S}-\mathrm{TB}}$ & Poly(TMOS) & $1 / 0.4 / 16$ & MAA/EGDMA/ACN & $\mathrm{AlBN} / 55^{\circ} \mathrm{C}, 60 \mathrm{~min}$ & [104] \\
\hline $\mathrm{D}, \underline{\mathrm{L}-\mathrm{THP}}$ & Poly(TMOS) & $1 / 3.3 / 13.3$ & MAA/EGDMA/ACN & $\mathrm{AIBN} / 55^{\circ} \mathrm{C}, 40 \mathrm{~min}$ & [104] \\
\hline Horseradish peroxidase & Poly(VPBA-co-PETA) & & Dopamine/Sodium phosphate buffer & $4^{\circ} \mathrm{C}, 12 \mathrm{~h}$ & [95] \\
\hline
\end{tabular}

* Template indicated in bracket when different from target or underlined for a mixture of targets.

$\mathrm{BMIM}^{+} \mathrm{PF}_{6}$ : 1-Butyl-3-methylimidazolium hexafluorophosphate; DMC: 5,7-Dimethoxycoumarin; PETA: Pentaerythritol triacrylate; TB: Tröger's base; THP: Tetrahydropalmatine; TMOS: Tetramethyl orthosilicate; VPBA: 4-vinylphenylboronic acid. 
Table 6. Performances of miniaturized monolithic MIPs used as stationary phase for separation.

\begin{tabular}{|c|c|c|c|c|c|c|c|c|}
\hline Target & Medium & $\begin{array}{l}\text { Dimensions } \\
\text { (L (I) x i.d.) * }\end{array}$ & $\begin{array}{l}\alpha \text { (RSD, } \\
\text { repetition } \\
\text { number) }\end{array}$ & IF & $\begin{array}{l}\text { Rs (RSD, } \\
\text { repetition } \\
\text { number) } \\
\end{array}$ & $\begin{array}{l}\mathbf{N} \\
\text { (plates/m) }\end{array}$ & $\begin{array}{l}\text { Others parameters: } \\
\text { RSD, repetition } \\
\text { number }\end{array}$ & Ref. \\
\hline \multicolumn{9}{|l|}{ CEC (Chiral separation) } \\
\hline 2,4-Aminopyridine & Pure medium & $31.2 \mathrm{~cm} \mathrm{(20) \times} 100 \mu \mathrm{m}$ & - & - & - & - & - & [79] \\
\hline R,S-Amlodipine & Pure medium & $41.5 \mathrm{~cm} \mathrm{(30)} \mathrm{x} 100 \mu \mathrm{m}$ & 5.83 & - & $\begin{array}{l}7.99(<4.75 \%, \\
\left.n_{B / B}=3\right)\end{array}$ & $\begin{array}{l}19,267(R) \\
18,667(S)\end{array}$ & - & [107] \\
\hline R,S-Naproxen & Pure medium & $31.2 \mathrm{~cm} \mathrm{(20)} \mathrm{x} 100 \mu \mathrm{m}$ & 5.74 & - & 8.82 & $12,000(S)$ & - & {$[98]$} \\
\hline $\begin{array}{l}\text { R,S-Ornidazole, R,S- } \\
\text { Secnidazole }\end{array}$ & Ornidazole tablets (ACN extract) & $52 \mathrm{~cm} \mathrm{(30)} \mathrm{x} 100 \mu \mathrm{m}$ & $\begin{array}{l}1.78 \\
1.45\end{array}$ & - & - & - & EOF: $<6 \%, n_{C / C}, n_{B / B}=3$ & [71] \\
\hline D,L-Phenylalanine & Pure medium & $38 \mathrm{~cm}(30) \times 100 \mu \mathrm{m}$ & - & $>2.0$ & - & - & - & {$[94]$} \\
\hline $\begin{array}{l}(S, R),(R, S),(S, S),(R, R)- \\
\text { Ractopamine }\end{array}$ & Pure medium & $-(-) \times 100 \mu \mathrm{m}$ & - & - & - & - & - & {$[72]$} \\
\hline R,S-Ropivacaine & Pure medium & $100 \mathrm{~cm}(91.5) \times 75 \mu \mathrm{m}$ & - & - & - & - & - & {$[86]$} \\
\hline $\mathrm{R}, \mathrm{S}-\mathrm{TB}$ & Pure medium & $33 \mathrm{~cm}(24.5) \times 75 \mu \mathrm{m}$ & - & - & 1.56 & & EOF: $<8 \%, n_{c / c}=3$ & [85] \\
\hline $\mathrm{R}, \mathrm{S}-\mathrm{TB}$ & Pure medium & $33 \mathrm{~cm}(8.5) \times 75 \mu \mathrm{m}$ & - & - & - & - & $\begin{array}{l}\text { EOF: }<4.7 \%, \mathrm{n}_{\mathrm{C} / \mathrm{C}}=3 ;< \\
6.3 \%, \mathrm{n}_{\mathrm{B} / \mathrm{B}}=3\end{array}$ & [104] \\
\hline D,L-THP & Pure medium & $33 \mathrm{~cm} \mathrm{(24.5)} \mathrm{x} 75 \mu \mathrm{m}$ & - & - & 1.43 & & EOF $:<8 \%, \mathrm{n}_{\mathrm{c} / \mathrm{c}}=3$ & {$[85]$} \\
\hline D,L-THP & Pure medium & $33 \mathrm{~cm}(8.5) \times 75 \mu \mathrm{m}$ & - & - & 1.08 & $\begin{array}{l}19,857(D) \\
3,993(L)\end{array}$ & $\begin{array}{l}\text { EOF: }<4.7 \%, \mathrm{n}_{\mathrm{C} / \mathrm{C}}=3 ;< \\
6.3 \%, \mathrm{n}_{\mathrm{B} / \mathrm{B}}=3\end{array}$ & [104] \\
\hline D,L-Tyrosine & Pure medium & $5 \mathrm{~cm} \mathrm{(-)} \times 25 \mu \mathrm{m}$ & - & - & 2.40 & - & $\operatorname{tr}: 3.2-4.2 \%, \mathrm{nc}_{\mathrm{c}}=6$ & [73] \\
\hline D,L-Tyrosine & Pure medium & $38 \mathrm{~cm}(30) \times 100 \mu \mathrm{m}$ & - & $>2.0$ & - & - & - & {$[94]$} \\
\hline D,L-Tryptophan & Pure medium & $38 \mathrm{~cm}(30) \times 100 \mu \mathrm{m}$ & - & $>2.0$ & - & - & - & {$[94]$} \\
\hline \multicolumn{9}{|l|}{ CEC (Analog separation) } \\
\hline Acephate, Phosphamidon & Cucumber, Letuce ( $\mathrm{H}_{2} \mathrm{O}$ extract) & $55 \mathrm{~cm}(44) \times 75 \mu \mathrm{m}$ & - & - & - & - & $\begin{array}{l}\text { Area: } 3.9-7.4 \%, \mathrm{n}_{\mathrm{D} / \mathrm{D}}= \\
4\end{array}$ & {$[35]$} \\
\hline $\begin{array}{l}\text { Carbaryl, Fenobucarb, } \\
\text { Metolcarb }\end{array}$ & Pure medium & $30.2 \mathrm{~cm} \mathrm{(15)} \mathrm{x} 100 \mu \mathrm{m}$ & $\begin{array}{l}4.62-5.96(< \\
10.3 \%, \mathrm{n}_{\mathrm{c} / \mathrm{c}}= \\
\text { 3) }\end{array}$ & $\begin{array}{l}7.57 \text { (Car) } \\
1.27 \text { (Fen) } \\
1.64 \text { (Met) }\end{array}$ & - & - & $\mathrm{tr}_{\mathrm{r}}:<4.5 \%, \mathrm{nc}_{\mathrm{c}} \mathrm{c}=3$ & {$[97]$} \\
\hline Dopamine & Banana (MeOH extract) & $36 \mathrm{~cm} \mathrm{(27)} \mathrm{x} 100 \mu \mathrm{m}$ & - & 2.0 & - & - & $\begin{array}{l}\mathrm{t}_{\mathrm{r}}: 0.69-1.96 \%, \mathrm{n}_{\mathrm{B} / \mathrm{B}}= \\
3^{*}\end{array}$ & [93] \\
\hline
\end{tabular}


Histamine, Serotonin,

Dopamine, Histidine, 5-HT

Sulfamethazine

Thiabendazole

Trichlorfon

Trietazine

YPLG, Oxytocin
Pure medium

Citrus / Orange (ACN extract)

Cucumber / Cauliflower / Leek

( $\mathrm{H}_{2} \mathrm{O}$ extract)

Pure medium

Pure medium

\section{$-(-) \times 100 \mu \mathrm{m}$}

$50 \mathrm{~cm}(8.5) \times 100 \mu \mathrm{m}$

$35 \mathrm{~cm}(27.5) \times 100 \mu \mathrm{m}$

$36 \mathrm{~cm} \mathrm{(27)} \times 100 \mu \mathrm{m}$

$31.2 \mathrm{~cm}(20) \times 100 \mu \mathrm{m}$
3.04

\section{6,500}

(Serotonin)

EOF: $<9.1 \%, \mathrm{n}_{\mathrm{C} / \mathrm{C}}=3 ;<\quad[96]$

$14.5 \%, \mathrm{n}_{\mathrm{B} / \mathrm{B}}=3$

$\mathrm{t}_{\mathrm{r}}: 0.9-2.6 \%, \mathrm{n}=5$

Area: $4.5 \%, n=5$

22,995

(YPLG)

16,952

(Oxy)

YPLG, YPGL

Pure medium

$31.2 \mathrm{~cm} \mathrm{(20)} \mathrm{x} 100 \mu \mathrm{m}$

3.72

30,000

$t_{r}:<3.47 \%, n=3$

[108]

Dopamine, (t)-

$70 \mathrm{~cm} \mathrm{(50)} \mathrm{x} 75 \mu \mathrm{m}$

180,000

Epinephrine, (-)-

Isoproterenol, ( \pm )

Octopamine, $( \pm)$ -

Synephrine

R,S-Ornidazole,

Pure medium

$51 \mathrm{~cm} \mathrm{(30)} \mathrm{x} 100 \mu \mathrm{m}$

$38(\mathrm{R} / \mathrm{S})$

$60,000-$

$\mathrm{t}_{\mathrm{r}}:<6.1 \%, \mathrm{n}_{\mathrm{c} / \mathrm{c}}=3$

\section{Metronidazole}

Secnidazole, Ronidazole

Tinidazole, Dimetridazole

D,L-Tyrosine, D, L-Alanine,

$D, L-P h e n y l a l a n i n e, ~ D, L-$

Pure medium

$-(-) \times 100 \mu m$

$1.00-2.64$

$>1.21$ (Analog)

Tryptophan, Cbz-D,L-

Tyrosine

\section{nanoLC}

Bupivacaine, Mepivacaine,

Pure medium

$5 \mathrm{~cm} \times 100 \mu \mathrm{m}$

$14-43$

[105]

-Ropivacaine

Bupivacaine

Pure medium

$4 \mathrm{~cm} \times 320 \mu \mathrm{m}$

$25 \mathrm{~cm} \times 100 \mu \mathrm{m}$

2.76

$\mathrm{k}: 4.07 \%, \mathrm{n}_{\mathrm{B} / \mathrm{B}}=3$

$-$

$-$


* $L(I) \times$ i.d.: total length (effective length for CEC in $\mathrm{cm}$ ) $x$ internal diameter.

5-HT: 5-Hydroxytryptophan; Cbz: Carboxybenzyl; k: Retention factor; $\mathrm{n}_{\mathrm{B} / \mathrm{B}}$ : Batch-to-batch; $\mathrm{n}_{\mathrm{C} / \mathrm{C}}$ : Column-to-column; TB: Tröger's base; THP: Tetrahydropalmatine; $t_{r}$ : Retention time; YPGL: Tyrosine-Proline-Glycine-Leucine; YPLG: Tyrosine-Proline-Leucine-Glycine. 
Table 7. Performances of monolithic MIPs prepared in capillaries, used as extraction sorbent, and ordered by the successive separation methods.

\begin{tabular}{|c|c|c|c|c|c|c|c|c|}
\hline Target & Medium & $\begin{array}{l}\text { Dimensions } \\
(\text { L x i.d.) }\end{array}$ & $\mathbf{V}_{\mathbf{P}}$ & $\begin{array}{l}\text { Binding capacity } \\
\text { (MIP/NIP)* }\end{array}$ & IF & EF & $\begin{array}{l}\text { Recovery (RSD, repetition } \\
\text { number) }\end{array}$ & Ref. \\
\hline \multicolumn{9}{|l|}{ LC - off-line mode } \\
\hline Auramine $\mathrm{O}$ & Shrimp (MeOH extract) & $10 \mathrm{~cm} \times 500 \mu \mathrm{m}$ & $1.5 \mathrm{~mL}$ & $0.722 / 0.147 \mu \mathrm{g} \mathrm{mg}^{-1}$ & - & 73 & $\begin{array}{l}\text { MIP: } 91-92 \%(2.1-4.4 \%, n=3) \\
\text { NIP: } 13 \% *\end{array}$ & [81] \\
\hline Bisphenol A, Nonyl phenol & Fish (MeOH extract) & $\begin{array}{l}4 \mathrm{~cm} \times 500 \mu \mathrm{m} \\
\text { (insert in a chip) }\end{array}$ & $8 \mathrm{~mL}$ & $0.391 / 0.143 \mu \mathrm{g} \mathrm{mg}^{-1}$ & - & $92-113$ & $\begin{array}{l}\text { MIP: } 82-92 \%\left(3.8-4.1 \%, n_{c} / \mathrm{c}=3\right) \\
\text { NIP: } 30-32 \% *\end{array}$ & [99] \\
\hline Aflatoxin $B_{1}$ & $\begin{array}{l}\text { Peanut }\left(\mathrm{MeOH} / \mathrm{H}_{2} \mathrm{O}\right. \\
\text { extract, } 80 / 20)\end{array}$ & $10 \mathrm{~cm} \times 500 \mu \mathrm{m}$ & $5 \mathrm{~mL}$ & $0.442 / 0.0917 \mathrm{ng} \mathrm{mg}^{-1}$ & - & 71 & MIP: $80-91 \%\left(1.2-3.8 \%, \mathrm{n}_{D / D}=3\right)$ & {$[34]$} \\
\hline Flumequine & $\begin{array}{l}\text { Fish (ACN/ Acetic acid } \\
\text { extract, 90/10) }\end{array}$ & $10 \mathrm{~cm} \times 500 \mu \mathrm{m}$ & $2.5 \mathrm{~mL}$ & $61.74 / 8.00 \mathrm{ng} \mathrm{mg}^{-1}$ & - & 40 & MIP: $81-95 \%\left(3.8-5.4 \%, \mathrm{n}_{D / D}=3\right)$ & [101] \\
\hline Guanosine, 8-OHdG & Urine (ACN extract) & $4.8 \mathrm{~cm} \times 530 \mu \mathrm{m}$ & $1 \mathrm{~mL}$ & - & - & $76-100 *$ & MIP: $81-86 \%\left(3.9 \%, \mathrm{n}_{\mathrm{B} / \mathrm{B}}=5\right)$ & [31] \\
\hline $\begin{array}{l}\text { Ciprofloxacin, Difloxacin, } \\
\text { Danofloxacin, Enrofloxacin }\end{array}$ & Milk (Dil. x10) & $8 \mathrm{~cm} \times 530 \mu \mathrm{m}$ & $1 \mathrm{~mL}$ & $36.0 / 23.5 \mu \mathrm{mol} \mathrm{g}^{-1}$ & 3.1 & - & $\begin{array}{l}\text { MIP: } 92-98 \%\left(2.4-5.5 \%, \mathrm{n}_{\mathrm{B} / \mathrm{B}}=4\right. \\
\left.* ; 1.9-5.9 \%, \mathrm{n}_{\mathrm{D} / \mathrm{D}}=3\right) \\
\text { NIP: } 23-66 \% *\end{array}$ & [69] \\
\hline Rhodamine B & Chili powder ( $\mathrm{H}_{2} \mathrm{O}$ extract) & $\begin{array}{l}3.5 \mathrm{~cm} \times 500 \mu \mathrm{m} \\
\text { (insert in a chip) }\end{array}$ & $8 \mathrm{~mL}$ & $1.994 / 0.282 \mu \mathrm{g} \mathrm{mg}^{-1}$ & - & 110 & MIP: $83-88 \%\left(2.5-3.1 \%, \mathrm{n}_{D / D}=6\right)$ & [102] \\
\hline Safranin T & Wolfberry (MeOH extract) & $10 \mathrm{~cm} \times 500 \mu \mathrm{m}$ & $4 \mathrm{~mL}$ & $66 / 6 \mathrm{ng} \mathrm{mg}^{-1}$ & - & $>90$ & $\begin{array}{l}\text { MIP: } 91-93 \%\left(3.4-3.9 \%, \mathrm{n}_{D / D}=6\right) \\
\text { NIP: } 23 \% *\end{array}$ & [78] \\
\hline $\begin{array}{l}\text { Carbendazim, } \\
\text { Thiabendazole, } \\
\text { Fuberidazole }\end{array}$ & Citrus (ACN extract) & $8 \mathrm{~cm} \times 500 \mu \mathrm{m}$ & $4 \mathrm{~mL}$ & $58.01 / 10 \mathrm{ng} \mathrm{mg}^{-1}$ & - & $9.4-23$ & MIP: $85-98 \%\left(2.5-8.1 \%, \mathrm{n}_{D / D}=3\right)$ & [103] \\
\hline \multicolumn{9}{|l|}{ CE - off-line mode } \\
\hline $8-\mathrm{OHdG}$ & Urine (ACN extract) & $4.8 \mathrm{~cm} \times 530 \mu \mathrm{m}$ & $1 \mathrm{~mL}$ & - & - & $\begin{array}{l}73(\mathrm{MIP}) * \\
41(\mathrm{NIP}) *\end{array}$ & MIP: $85 \%(4.7 \%, n=6)$ & [33] \\
\hline Rose bengal & $\begin{array}{l}\text { Brown sugar (MeOH } \\
\text { extract) }\end{array}$ & $10 \mathrm{~cm} \times 500 \mu \mathrm{m}$ & $2 \mathrm{~mL}$ & $1.314 / 0.531 \mu \mathrm{g} \mathrm{mg}^{-1}$ & - & 64 & $\begin{array}{l}\text { MIP: } 90 \%\left(3.6-4.0 \%, n_{D} / D=6\right) \\
\text { NIP: } 22 \% *\end{array}$ & {$[76]$} \\
\hline \multicolumn{9}{|l|}{ SDS-PAGE - off-line mode } \\
\hline Horseradish peroxidase & Human serum (Dil. x500) & $25 \mathrm{~cm} \times 100 \mu \mathrm{m}$ & $75 \mu \mathrm{L}$ & $4.56 / 1.65 \mu \mathrm{g} \mathrm{mg}^{-1}$ & $2.76 *$ & - & - & [95] \\
\hline Lysozyme & Human serum (Dil. x500) & $25 \mathrm{~cm} \times 75 \mu \mathrm{m}$ & $40 \mu \mathrm{L}$ & $3.864 / 2.015 \mu \mathrm{g} \mathrm{mg}^{-1}$ & - & - & - & {$[90]$} \\
\hline
\end{tabular}




\begin{tabular}{|c|c|c|c|c|c|c|c|c|}
\hline Baicalin & $\begin{array}{l}\text { Scutellaria baicalensis } \\
\text { (ACN/DMSO extract, } \\
90 / 10 \text { ) }\end{array}$ & $25 \mathrm{~cm} \times 250 \mu \mathrm{m}$ & $500 \mu \mathrm{L}$ & - & 2.2 & - & - & [91] \\
\hline Cannabidiol, $\triangle 9-\mathrm{THC}$ & $\begin{array}{l}\text { Human plasma } \\
\text { (Concentrated } x 6 \text { ) }\end{array}$ & $10 \mathrm{~cm} \times 530 \mu \mathrm{m}$ & $10 \mu \mathrm{L}$ & $148.05 \mathrm{ng} \mathrm{cm}^{3} /-$ & - & - & - & [70] \\
\hline 8-OHdG & Urine (ACN extract) & $14.5 \mathrm{~cm} \times 250 \mu \mathrm{m}$ & $1 \mathrm{~mL}$ & - & - & $102 *$ & MIP: $81-84 \%\left(<4.7 \%, \mathrm{n}_{\mathrm{D} / \mathrm{D}}=4\right)^{*}$ & [32] \\
\hline $\begin{array}{l}\text { SQX, SMZ, SMD, } \\
\text { Mequindox, Quinocetone }\end{array}$ & $\begin{array}{l}\text { Chicken, Pork, Egg } \\
\text { (ACN/Toluene/n-Hexane } \\
\text { extract) }\end{array}$ & $12 \mathrm{~cm} \times 320 \mu \mathrm{m}$ & & - & - & $46-211 *$ & $\begin{array}{l}\text { MIP: } 70-108 \%\left(3.6-7.5 \%, \mathrm{n}_{B / B}=\right. \\
3)^{*}\end{array}$ & [89] \\
\hline \multicolumn{9}{|l|}{ CE - on-line mode } \\
\hline Auramine $\mathrm{O}$ & Shrimp (MeOH extract) & $\begin{array}{l}2.7 \mathrm{~cm} \times 500 \mu \mathrm{m} \\
\text { (insert in a chip) }\end{array}$ & $440 \mu \mathrm{L}$ & $0.722 / 0.147 \mu \mathrm{g} \mathrm{mg}^{-1}$ & - & 12 & MIP: $90-93 \%(2.6-4.7 \%, n=3)$ & {$[77]$} \\
\hline \multicolumn{9}{|l|}{ Nano LC - on line mode } \\
\hline Aflatoxins $\left(B_{1}, B_{2}, G_{1}, G_{2}\right)$ & Pure medium & $17 \mathrm{~cm} \times 100 \mu \mathrm{m}$ & $5 \mu \mathrm{L}$ & - & $2.44-3.37$ & - & - & {$[36]$} \\
\hline Cocaine & $\begin{array}{l}\text { Human serum (Diluted } \\
\times 2 \text { ), Saliva (Direct } \\
\text { injection) }\end{array}$ & $5 \mathrm{~cm} \times 100 \mu \mathrm{m}$ & $50-100 \mathrm{~nL}$ & - & $3.2 \pm 0.5 *$ & - & $\begin{array}{l}\text { MIP: } 89-100 \%\left(3.8-5.8 \%, n_{B / B}=\right. \\
3) \\
\text { NIP: } 9-23 \% *\end{array}$ & {$[82]$} \\
\hline
\end{tabular}

* Results obtained in pure medium.

8-OHdG: 8-Hydroxy-2'-deoxyguanosine; $\mathrm{n}_{\mathrm{B} / \mathrm{B}}$ : Batch-to-batch; $\mathrm{n}_{\mathrm{C} / \mathrm{C}}$ : Column-to-column; $\mathrm{n}_{\mathrm{D} / \mathrm{D}}$ : Day-to-day; SMD: Sulfametoxydiazine; SMZ: Sulfamethoxazole; SQX: Sulfaquinoxaline; $V_{\mathrm{p}}$ : Volume of percolation; $\Delta 9-\mathrm{THC}$ : $\Delta 9$ - tetrahydrocannabinol. 
